

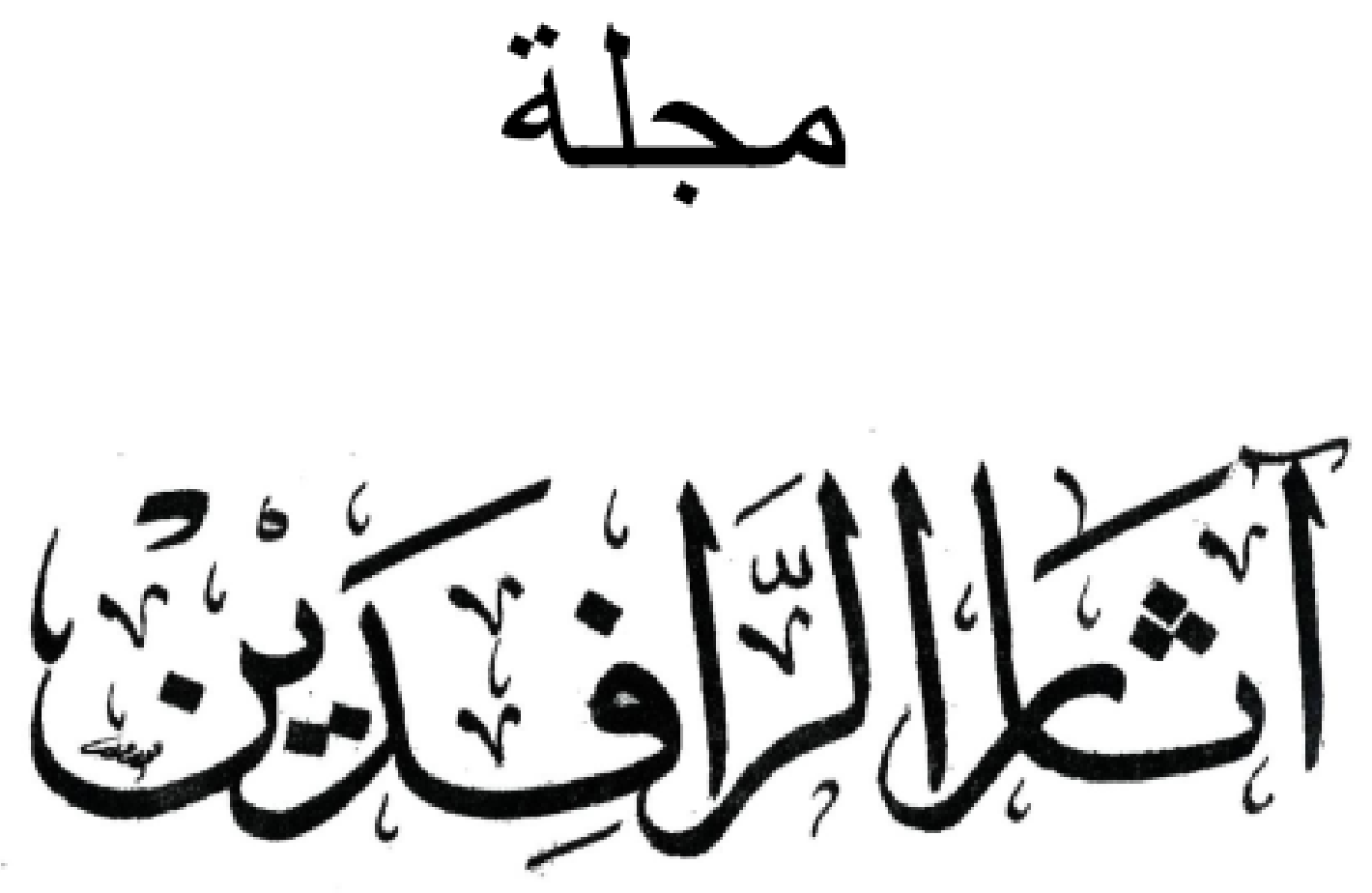

هجلة علمية همكمة تبحث في آثار العراق و الشرق الأدنى القديم تصدر عن كلية الآثار في جاهعة الموصل

E-Mail: uom.atharalrafedain@ gmail.com البريد الاكتروني

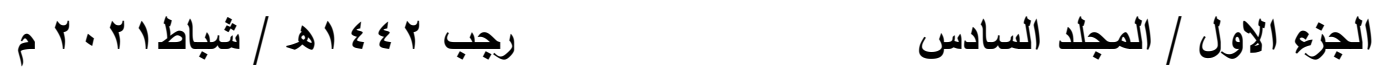

$$
\begin{aligned}
& \text { رقم الايداع في دار الكتب والوثائق بيغداد } \\
& \text { r. I السنة (IVIr) }
\end{aligned}
$$





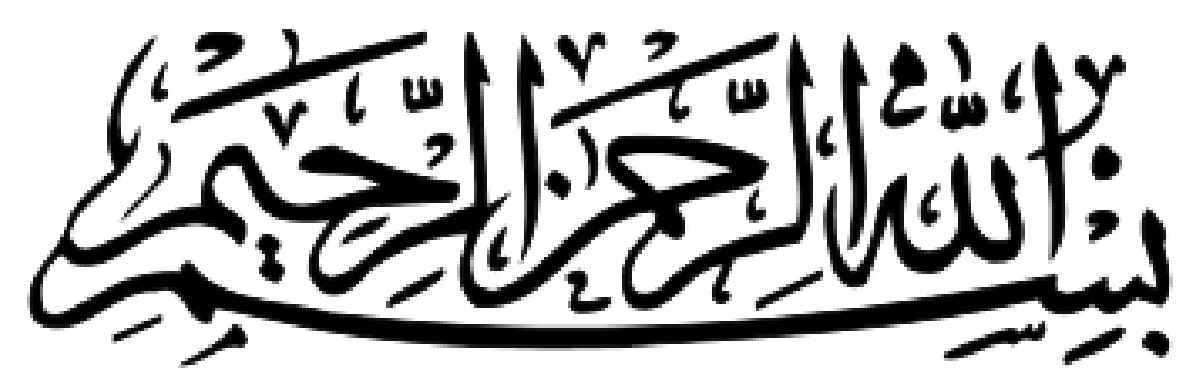





\section{هيأة التمرير}

أ. خالد سالم اسماءيل

رئيس التمرير

أ.م. هسنين حيدر عبد الواحد

الاعضاء

أ.د. اليزابيث ستون

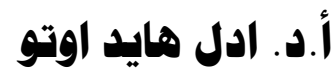

أ.د. والتز سلابيركر

أ.د. نيكولو هاركيتي

أ.د. هديب حياوي عبد الكريم

أ.د. جواد هطر الموسوي

أ.د. رفاه جاسم حمادي

أ.د. عادل هاشم علي

أ.م.د. ياسمين عبد الكريم هممد علي

أ.م.د. فيسان هوفق رشيد

أ.م.د. هاني عبد الغني عبد الله 


$$
\begin{aligned}
& \text { هقوم اللغة العربية } \\
& \text { أ.م.د. همن يميى هصمد }
\end{aligned}
$$

$$
\begin{aligned}
& \text { هقوم اللغة الانكليزية } \\
& \text { م.A. عمار احمد هميمود } \\
& \text { قسم الترجمة / كلية الآداب / جاهعة الموصل }
\end{aligned}
$$

$$
\text { د. تصهيم الغلاف البميلي }
$$




\section{قواعد النشر في هبلة آثار الرافدين}

$$
\begin{aligned}
& \text { 1- تقبل المجلة البحوث العلمية التي تقع في تخصصات: } \\
& \text { • علم الاثار بفرعيه القديم والإسلامي • } \\
& \text { • • اللغات القديمة بلهجاتها و الدراسات الدقارنة. } \\
& \text { الكتابات المسمارية و الخطوط القديمة . } \\
& \text { ه الدراسات التاريخية والحضارية . }
\end{aligned}
$$

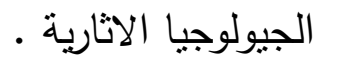

$$
\begin{aligned}
& \text { • تقنيات المسح الاثاري • }
\end{aligned}
$$

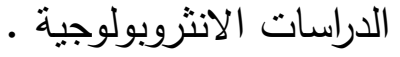

$$
\begin{aligned}
& \text { • الصيانة والتزميم الصنيم }
\end{aligned}
$$

r- تقدم البحوث الى المجلة باللغتين العببية أو الانكليزية .

r-يطبع البحث على ورق (A4)، وبنظام (2010 - word)، وبمسافات مزدوجة بين الاسطر ، وبخط Simplified Arabic للغة العربية، و Times New Roman للغة

$$
\text { الانكليزية، ويسلم على قرص ليزري (CD) ، وبنسختين ورقيتين. }
$$

ع- يطبع عنوان البحث في وسط الصفحة يليه اسم الباحث ودرجته العلمية ومكان عمله

$$
\text { كاملاً والبريد الالكتروني (e-mail). }
$$

0- يجب ان يحتوي البحث ملخصا باللغتين العربية والانكليزية على ان لا تزيد عن (· (1) كلمة.

1-يحتوي ملخص البحث بالإنكليزية على عنوان البحث واسم الباحث ودرجته العلمية ومكان عمله كاملاً والبريد الالكتروني له. V- تضمين البحث كلمات مفتاحية تتعلق بعنوان البحث ومضمونه. ^- ان لا يكون البحث قد تم نشره سابقا أو كان مقدما لنيل درجة علمية أو مستلاً من ملكية

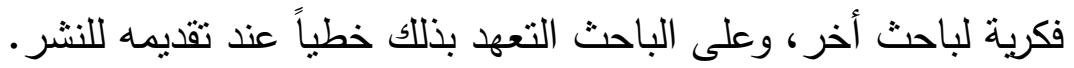
9- يلتزم الباحث باتباع الاسس العلمية السليمة في بحثه. • 1- يلزم الباحث بتعديل فقرات بحثه ليتناسب مع مقترحات الخبراء واسلوب النشر في 
11- لا تتجاوز عدد صفحات البحث عن (ro)، صفحة وفي حال تجاوز العدد المطلوب يتكفل الباحث بدفع مبلغاً اضافياً عن كل صفحة اضافية.

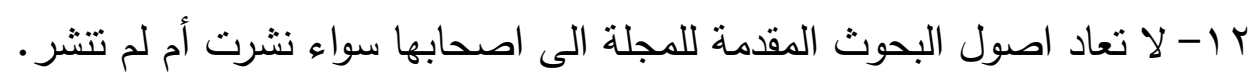
با ا-ترقم الجداول والاشكال على التوالي وبحسب ورودها في البحث، وتزود بعناوين، وتقدم بأوراق منفصلة وتقام المخططات بالحبر الاسود والصور تكون عالية الدقة. ـ ا-تكتب ارقام الهوامش بين قوسين وترد متسلسلة في نهاية البحث. 10-يشار الى اسم المصدر كاملاً في الهامش مع وضع مختصر المصدر بين قوسين في نهاية الهامش.

17 - يتحمل الباحث تصحيح ما يرد في بحثه من اخطاء لغوية وطباعية.

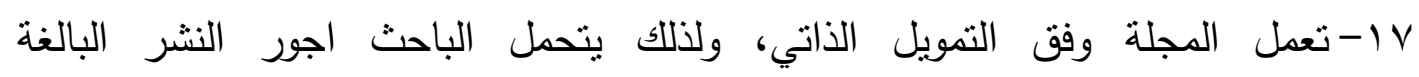

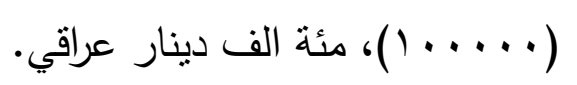

11 ا- يزود كل باحث بمستل من بحثه، أما نسخة المجلة كاملة فتطلب من سكرتارية المجلة لقاء ثمن تحدده هيأة التحرير . 9 ا - ترسل البحوث على البريد الالكتروني للمجلة: uom.atharalrafedain@gmail.com 


\section{ثبت المحتويات}

\begin{tabular}{|c|c|c|}
\hline 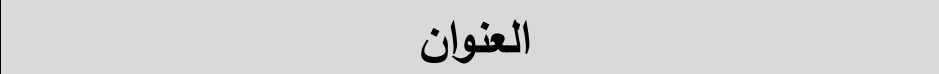 & اسم الباحث & الصفحة \\
\hline 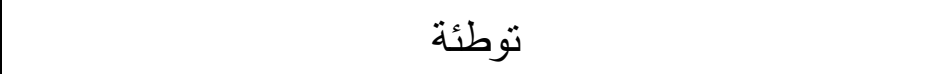 & أ. خالد سالم اسماعيل & 1 \\
\hline من ملاحم ملوك بلاد الرافدين في الألف الثاني والأول قبل & عدي عبدالوهاب النعيمي & $19-4$ \\
\hline "الفِِيْة" في النصوص الأكّدية & أ. د. فاروق إسماعيل & $\leqslant \varepsilon-r)$ \\
\hline هواجس خوف الآشوريين وقلقهم من الأرواح الشريرة & أ.ديم محمد صالح مصطفى صفوان سامي سعيد & $V \cdot-\varepsilon 0$ \\
\hline مدينة سيواس قبل حكم السلاجقة & أ.د. ياسر عبد الجواد المشهداني & $91-v 1$ \\
\hline التتقيات الروسية في منطقة سنجار شمال العراق & أ. أ.م.د. محمد كامل روكان & $11 \leqslant-94$ \\
\hline قالبيوت السكنية من العصر الاشوري الحديث (1) مواقع منتخبة من منطقة مشروع سد مكحول r (1) & أ.م.د. باسمين عبد الكريم محمد علي السامرائي & $1 r v-110$ \\
\hline من الجوامع التزاثية في مدينة سنجار & أ.م.د حيدر فرحان حسين الصبيحاوي نومان الثمري & $17 \leqslant-119$ \\
\hline 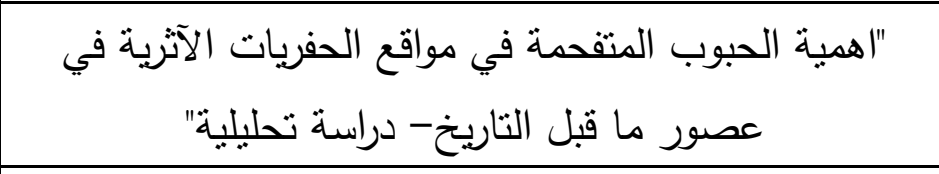 & أ.م.د. حسين يوسف حازم & $110-170$ \\
\hline 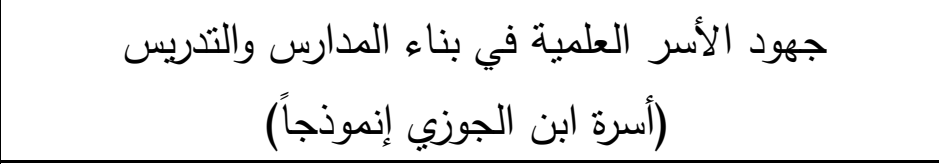 & 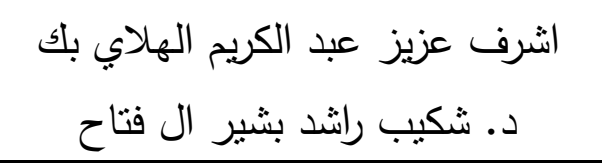 & r) $r-1$ AV \\
\hline دوافع تحنيط الحيوانات عند المصريين القدماء & أ.م.دد وسناء حسون يونس الاغا & 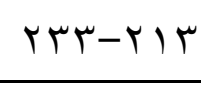 \\
\hline وصولات انجاز اللبن من مدينة بيكاسي " تل ابوعنتيك" - " & د.آرام جلال حسن الهموندي & rTI-rTO \\
\hline نصوص اقتصادية غير منشورة من سلالة اور الثالثة & م.د مهند خلف جمين الثمري & rV9-rฯr \\
\hline الثياطين والأرواح الثريرة في العراق القيم في ضوء النصوص المسمارية & 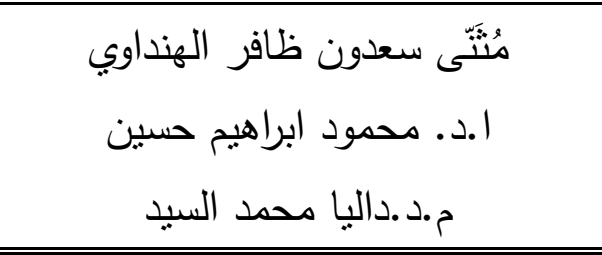 & $r \cdot r-r \wedge l$ \\
\hline
\end{tabular}





$$
\text { " دورلات انجاز اللبن من مدينة بيكاسي " تل ابوعنتيك" }
$$

\section{aram.hassan@su.edu.krd}

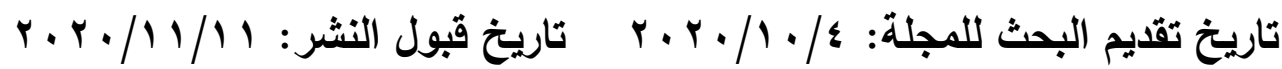

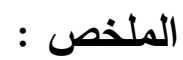

من بين المكتشفات الأثريـة في مدينـة بيكاسي والمحفوظة حاليا في خزائن المتحف

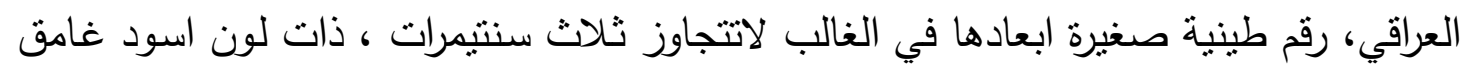

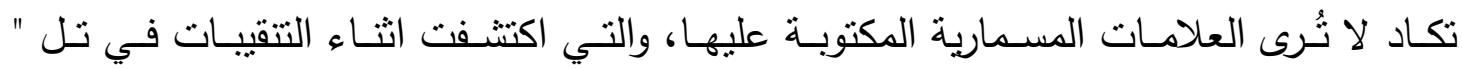
ابوعنتيك" في المواسم الخمسة.

ويبدو ان معظم الرقم الطينية قيد الدراسـة في هذه البحث تعود لثخص واحد اسمه

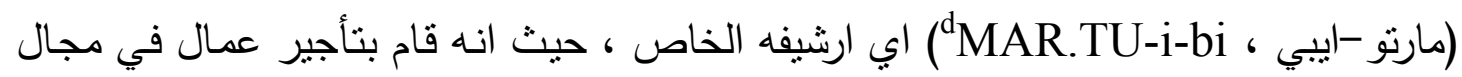
صناعة اللبن لإعداد كمية كبيرة من اللبن طيلة شهر تموز وهو الوقت المثالي لصناعة اللبن.

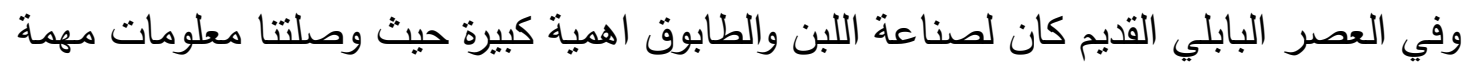

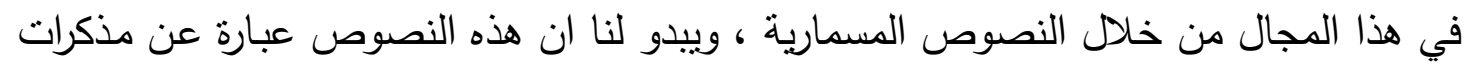
يومية لـ (مارتو - ايبي ) اذ نلاحظ ان معظم نصوص الدراسة في هذا البحث تعود لايام مختلفة

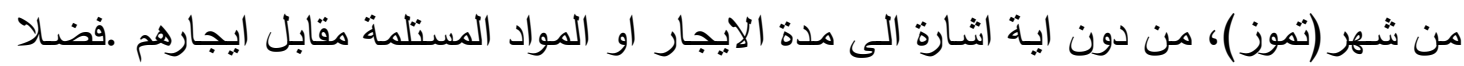

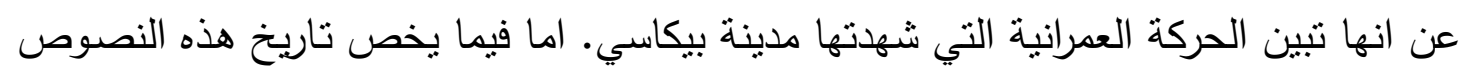

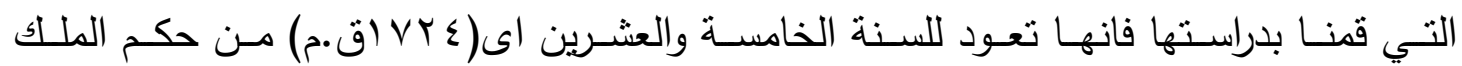

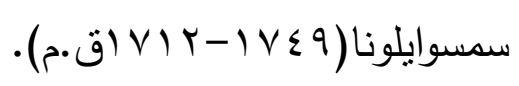

الكلمات المفتاحية: نصوص مسمارية ، بيكاسي " ثل ابوعنتيك" ، العصر البابلي القديم ، اللبن ،

$$
\text { مارتو - ايبي. }
$$




\title{
The Brick Completion Receipts from the City of Pekasi, "Till Abu-Antik" \\ "An Analytical Study of Unpublished Cuneiform Texts"
}

\author{
Dr. Aram J. Hassan Hamawand \\ Lecturer At Archaeology Department \\ -College of Arts \\ University of Salahaddin-Erbil
}

\begin{abstract}
:
Between the finds discovered in the city of Pekasi and currently preserved in the treasuries of the Iraqi Museum was numbers of small tablet, its dimensions usually not exceeding three centimeters, with a dark black color, often invisible to the cuneiform signs written on it, all of it discovered during the excavations in Pekasi, "Till Abu-Antik" during five seasons.

It seems that most of the tablets under study in this research belong to one person named ( ${ }^{\mathrm{d}} \mathrm{MAR}$.TU-i-bi), that is meaning his own archive, as he hired workers in the Brick industry from different people, and it seems that he needed a large number of bricks, where we notice that he hired workers to manufacture brick throughout the month of July. The manufacture of bricks was of great importance from old Babylonian Period, as important information in this field reached us through cuneiform texts. It seems to us that these texts are daily diaries of ( ${ }^{\mathrm{d}}$ MAR.TU-i-bi), as we note that most of the texts of the study in this research date back to different days of The month of (July), without any indication of the duration of the lease or the materials received in return for their rent. In addition, it shows the urban movement witnessed by the city of Bekasi. As for the history of these texts that we have studied in this research, they go back to the twenty-fifth year (1724 BC) of the reign of King Samsu-iluna (1749-1712 BC).
\end{abstract}

Keywords: Cuneiform texts, Pekasi, "Till Abu-Antik", Old Babylonian period, Bricks, ${ }^{\mathrm{d}}$ MAR.TU-i-bi.

أبو عنتيك موقع اثري لم يسجل سابقا في قائمة المواقع الأثرية ، يقع على خط مستقيم

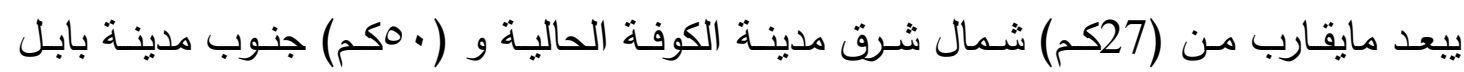

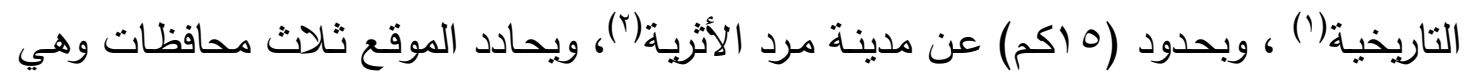

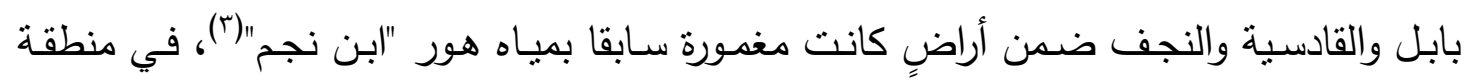

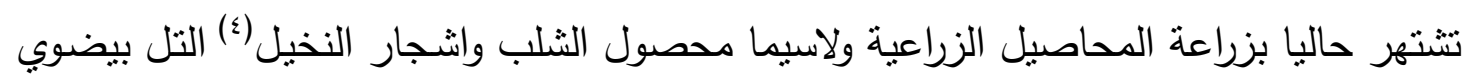




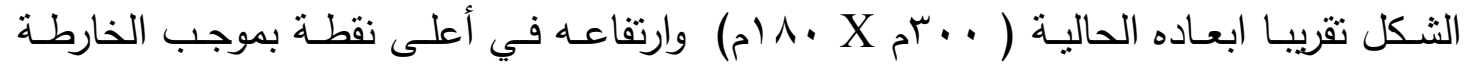

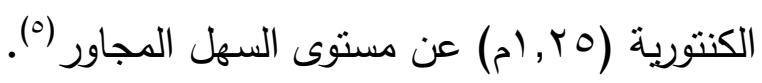

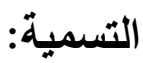

أبو عنتيك تسمية محلية محرفة من الكلمة الأنجليزية "Antiquity" التي تعني

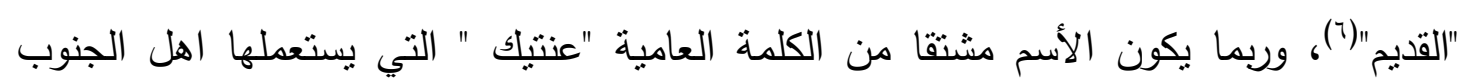

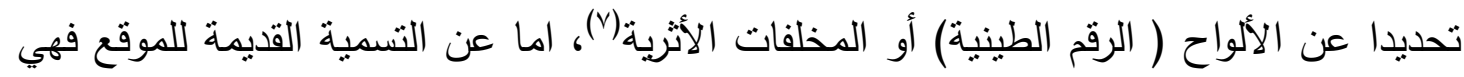

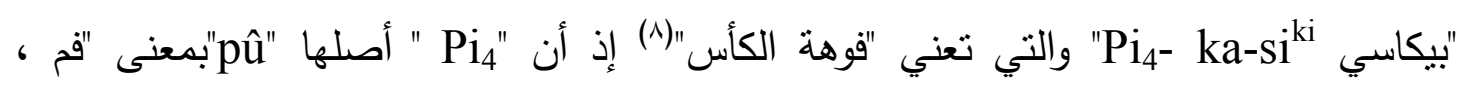

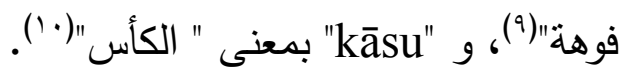
وقد كتب اسم هذه المدينة بعدة صيغ هي "(')"

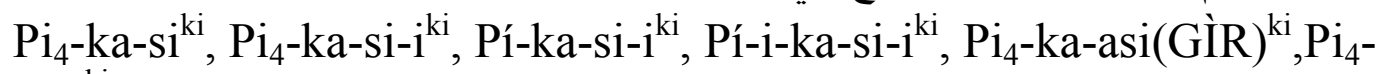
ka-as-i ${ }^{\mathrm{ki}}$

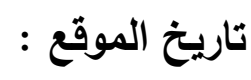

امـا بخصوص تاريخ المدينة ، يمكنتا القول ان المدينة كانت موجودة في زمن حكم

الملك " سين ـ ادينام Sin-idinnam

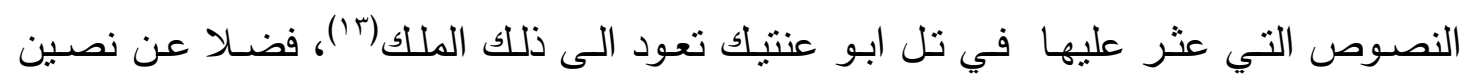

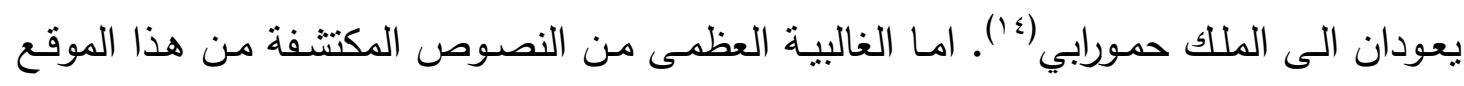

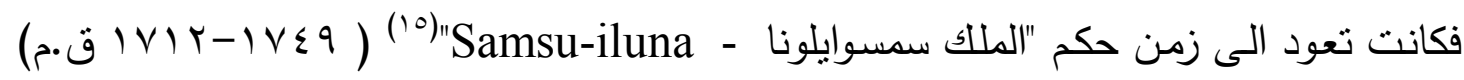

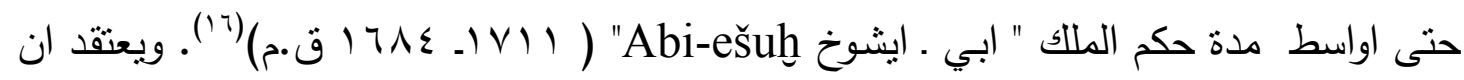

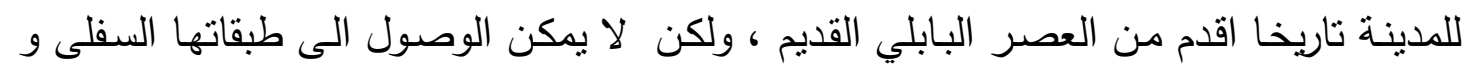

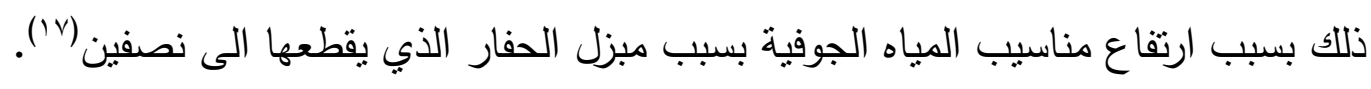

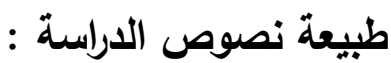

تتميز النصوص المسمارية قبد الدراسة باحجامها الصغيرة جداً والتي لا تتجاوز ثلاثة

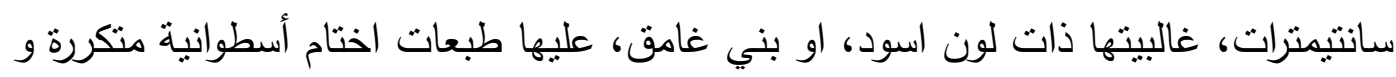
متداخلة لدرجة انه صعبت علينا في كثير من الاحيان قراءة العلامات المسمارية و فهمها.

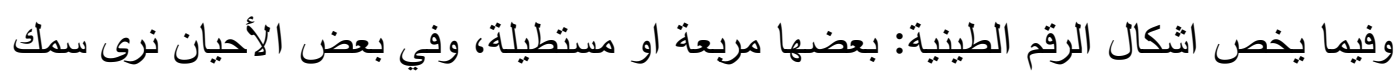

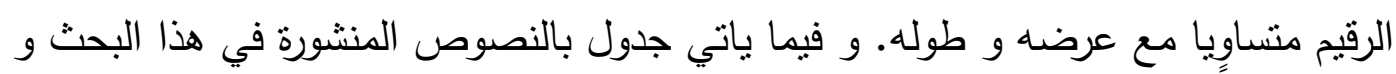




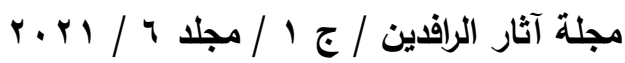

\begin{tabular}{|c|c|c|c|c|c|}
\hline \multicolumn{3}{|c|}{ القياسات } & \multirow{2}{*}{ رقم الحفريات } & \multirow{2}{*}{ رقم المتحف العر اقي } & \multirow[b]{2}{*}{ رانص } \\
\hline سمك & عرض & طول & & & \\
\hline 0, اسم & V Yוسم & V Yוسم & Y أبو عنتيك & ع.P 1 مr人To & 1 \\
\hline 9 9, اسم & 9, צוسم & T, بسم & $\begin{array}{l}\text { أبو عنتيك } \\
\text { SAMV }\end{array}$ & $\varepsilon \cdot \rho^{\prime \wedge r \Lambda \leqslant V}$ & $r$ \\
\hline كم & آ,"اسم & "اسم & 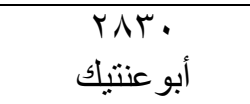 & ع.p $\mid \wedge \uparrow \wedge \varepsilon$. & $r$ \\
\hline 1, اسم & V Y Ywم & Y, זسم & $\begin{array}{l}\text { أبو عنتيك } \\
\text { RAMq }\end{array}$ & $\varepsilon \cdot \rho^{\prime \wedge r \wedge \leqslant q}$ & $\varepsilon$ \\
\hline 9, اسم & ^ג,זسم & 0, זسم & $\begin{array}{c}\text { أبو عنتيك } \\
\text { أب }\end{array}$ & E.P INr人or & 0 \\
\hline 0 اسم & V Y Ywم & Y, זسم & $\begin{array}{l}\text { أبو عنتيك } \\
\text { FAT }\end{array}$ & $\varepsilon \cdot \rho^{\prime} \backslash \wedge \uparrow \Sigma \varepsilon$ & 7 \\
\hline 1, اسم & 9, זسم & V , זسم & $\begin{array}{c}\text { أبو عنتيك } \\
\text { أبN| }\end{array}$ & 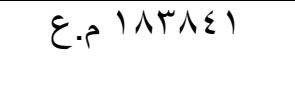 & V \\
\hline 9 (سم & V , זسم & "اسم & TAMT أبو عنتيك RAT & $\varepsilon \cdot p^{\prime \wedge r \wedge \leq r}$ & $\Lambda$ \\
\hline V Y, וسم & T, זسم & V Yוسم & 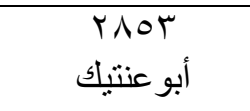 & ع.p $114 \wedge 09$ & 9 \\
\hline V Y, اسم & q, צسم & 1, זسم & 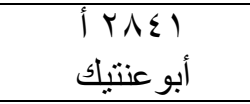 & E.P $\mid \wedge r \wedge 01$ & 1. \\
\hline
\end{tabular}

وكان التسلسل في نصوص الدراسة كالآتي:

1- إل عدد العمال صانعي اللبن (الطابوق).

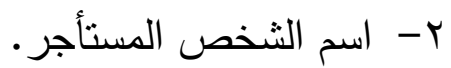

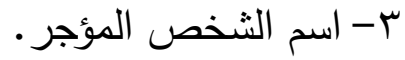

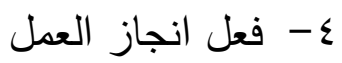

0- ت تاربخ اليوم والثهر والسنة.

جميع هذه النصـوص تعـود بتاريخها الى السـنة الخامسـة والعشـرين مـن حكم الملك

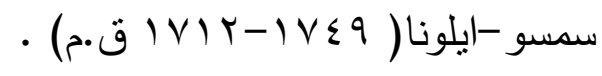

ويمكن ان نستعرض قراءة النص وتحليله بالثكل الآتي:

No. 1 (IM.183865)

Obv.

4 ERÍN la-bi-ni

A-wi-il- ${ }^{\mathrm{d}} \mathrm{Na}$-bi-um

a-na ${ }^{\mathrm{d}}$ MAR.TU-i-bi

Lo.ed.

il-li-ik 
Rev.

5- ITU ŠU.NUMUN.A U 1 KAM MU ALAM ${ }^{\text {giš }}$ TUKUL SİG.GI

$$
\begin{aligned}
& \text { الترجمة } \\
& \text { الوجه: } \\
& \text { ا - بـ (ع) (عمال) صانعي اللبن } \\
& \text { r- اويل - -نابيوم } \\
& \text { ب-لِ مارنو - سيبي }
\end{aligned}
$$

0- اليوم الأول من شهر تموز

7-سنة التمثال حامل السـلاح

" المعنى العام "

( مذكره (انجاز) عمل (ما) باربعة عمال من صناع اللبن من قبل "آويل - نابيوم"

الى "مارتو - ايبي"، النص مؤرخ باليوم والثهر والسنة )

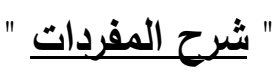

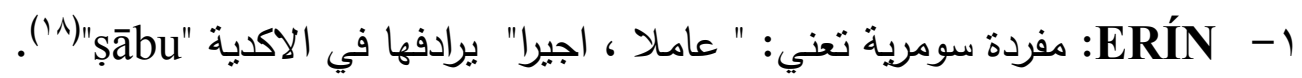
وان المفردة "ERÍN" تعني: "عاملا او أجيرا" اذا جاءت في النصوص الاقتصادية، وكذللك مع يع اسماء وقوائم العمال وهي بذلك مشابه لـ "UKU. UŠ" التي تعني عاملاً من نوع "redû" (9)" . ومن الممكن ان تسبق بعلامة دالة على المهن، فأذا حذقت او ابقيت فأنها لاتؤثر في المعنى

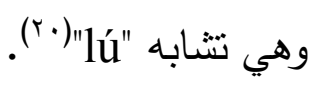
lābin̄̄ " الموجودة في هذا النص جاءت في حالة المضاف اليه "الجر "و و المفرديَ بصيغة الجمع وبذلك يكون المعنى " صُنّاع اللبن"، ومفردها " lābinu " بمعنى "صانع اللبن"( (r) ومما يجدر الأشارة اليه ان المفردة "lābin̄̄" ظهرت بهذه الصيخة فقط من ضمن نصوص مدينة "بيكاسي" وحتى انه في قاموس شيكاغو الآشوري لاتوجد فيه هذه الصيغة، وهذا شيء له اهميته الخاصة. حيث جاءت في قاموس شيكاغو الآشوري بصيغة "labin ana labinu" . 
Awīl- ${ }^{d}$ Na-bi-um (r الثائعة في العصر البابلي القديم(rr)

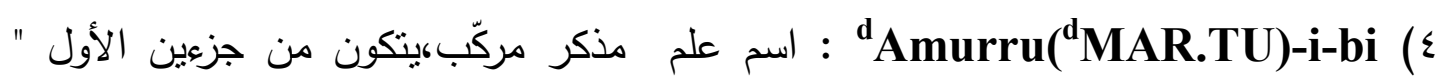

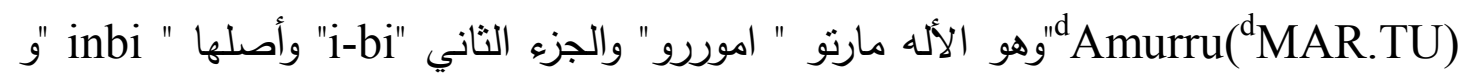

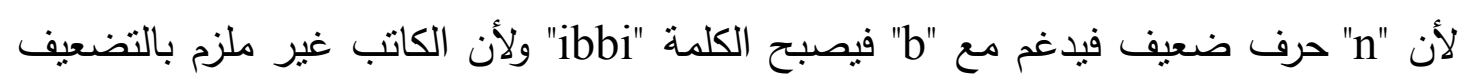

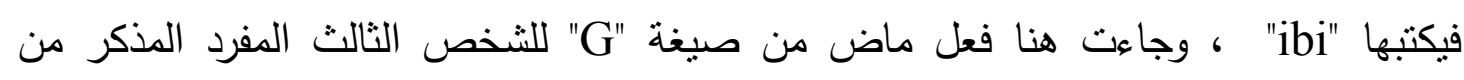

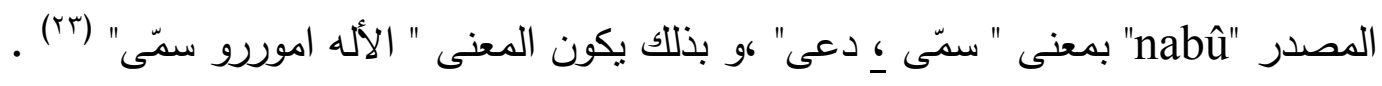

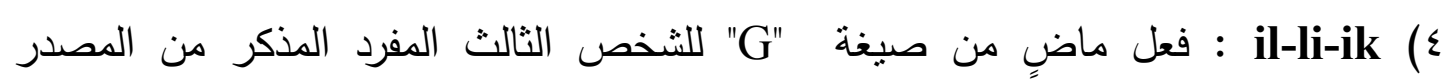
"alāku"

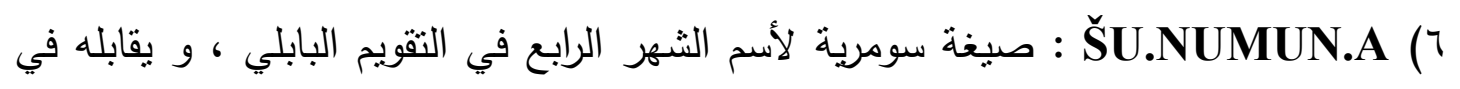

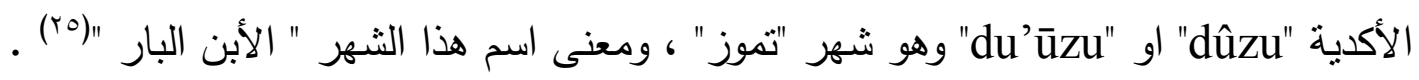

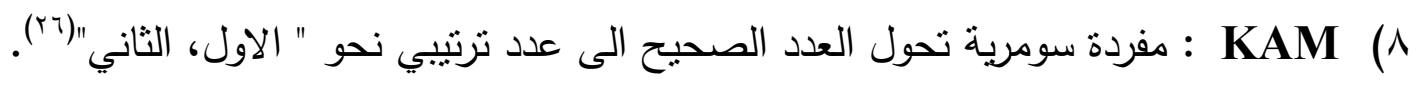

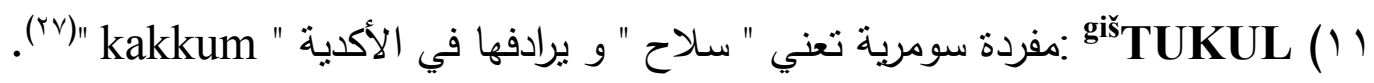
SIÌG.GI (I r مسك" (^)

ملاحظة : ان العلامة السومرية " SÌG " تقرأ ايضا بـ"SÀG" والتي تعطي نفس المعنى (ra).

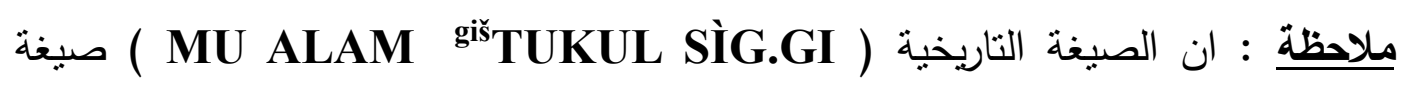

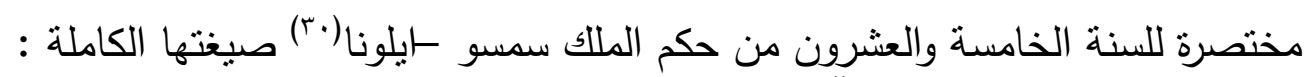

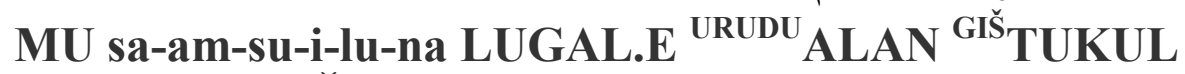
KU $_{3}$.SIG ${ }_{17}$ HUUŠ.A SIG $_{3}$.GE ME.GIM NAM.UR.SAG.GA.KA.NA

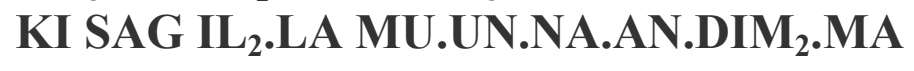

سنة سمسو -ايلونا الملك عمل تمثال من الذهب (بصورة ) واقف (بمثله) حامل السلاح

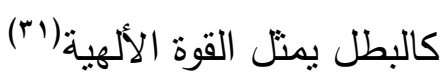

Obv.

\section{No.2 (IM.183847)}

2 ERÍN la-bi-ni ma-wi-i[1- ${ }^{\mathrm{d}}$ na-b]i-um

Rev. [a-na] ${ }^{\mathrm{d}}$ MAR.TU-i-bi il-li-ik

5- $\quad$ ITU S̆U.NUMUN.A U 43 KAM

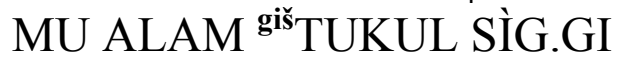


ا - (r) (عاملان من) صانعي اللبن

$$
\begin{aligned}
& \text { r- اويل -نابيوم }
\end{aligned}
$$

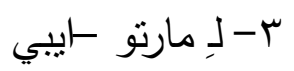

$$
\text { ع - عمل او أنجزَ }
$$

0- اليوم الثالث من شهر تموز

1- سنة التمثال حامل السلاح

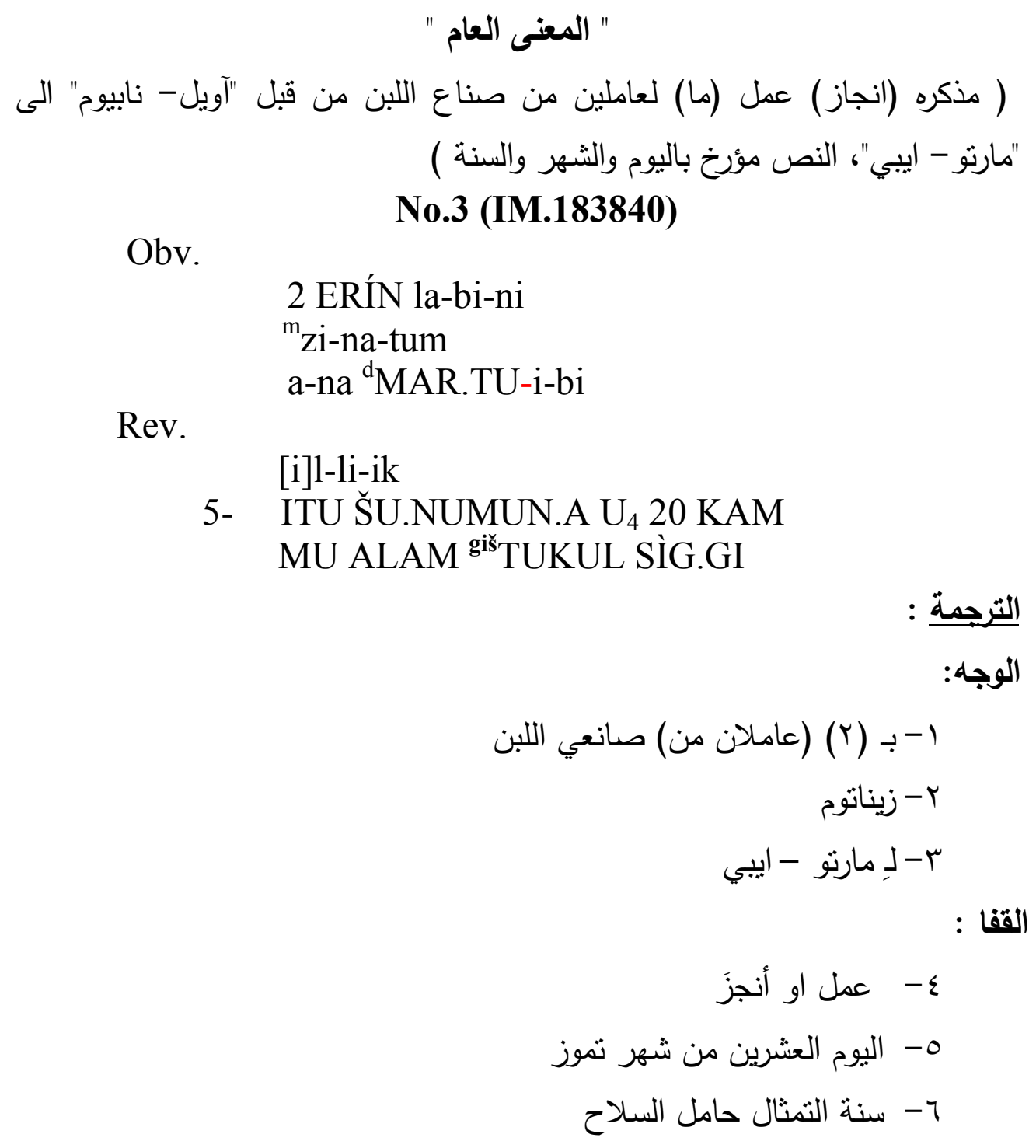




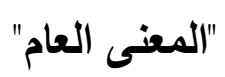

( مذكرة انجاز عمل (ما) لعاملين من صناع اللبن من قبل "زيناتوم" الى "مارتو -

ايبي"، النص مؤرخ باليوم والثنهر والسنة )

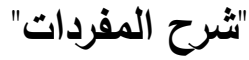

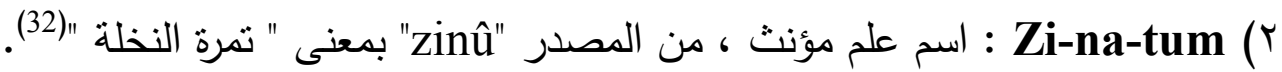
NO.4 (IM.183849)

Obv.

$$
\begin{aligned}
& 3 \text { ERÍN la-bi-ni } \\
& { }^{m} \text { be-la-nu-um } \\
& \text { a-na }{ }^{\mathrm{d}} \text { MAR.TU-i-bi }
\end{aligned}
$$

Lo.ed.

$$
\text { il-li-ik }
$$

Rev.

5- ITU ŠU.NUMUN.A U 420 KAM

MU ALAM ${ }^{\text {giš }}$ TUKUL SİG.GI

$$
\text { الوجه: }
$$$$
\text { 1-بـ (r) (عمال من) صانعي اللبن }
$$

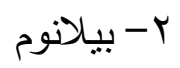

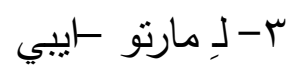

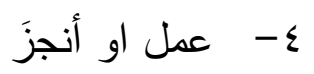

0- اليوم العشرون من شهر تموز

؟- سنة التمثال حامل السلاح

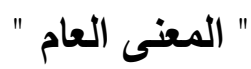

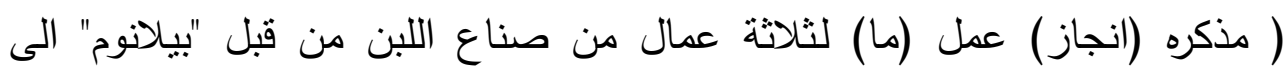

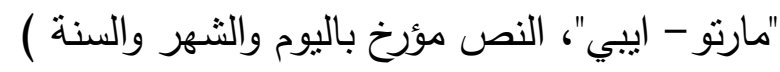


مe-la-nu-um (r "be-el-a-nu-um" "والذي يعني " الأله آنو السيد"(33).

\section{NO.5 (IM.183853)}

Obv.

$$
\begin{aligned}
& 2 \text { ERÍN la-bi-nu } \\
& \text { mbe-la-nu-um } \\
& \text { a-na }{ }^{\mathrm{d}} \text { MAR.TU-i-bi }
\end{aligned}
$$

Rev.

$$
\begin{aligned}
& \text { 5- } \quad \begin{array}{l}
\text { il-li-ik } \\
\text { ITU ŠU.NUMUN.A U }
\end{array} \text { 21 KAM } \\
& \text { MU ALAM giš TUKUL SİG.GI }
\end{aligned}
$$

$$
\text { اللتهجمة : }
$$$$
\text { 1-بـr (عاملان من) صانعي اللبن }
$$$$
\text { r- بيلانوم }
$$

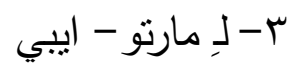

$$
\text { - - - عمل او انجز }
$$$$
\text { 0- اليوم الواحد والعشرون من شهر تموز }
$$

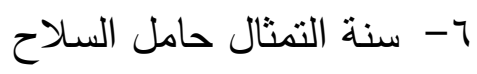

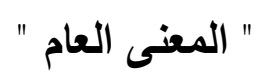

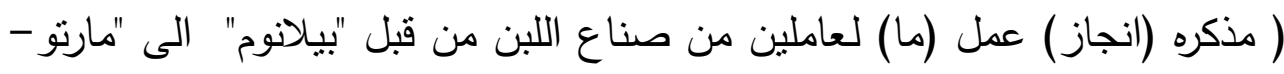

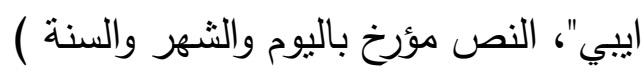

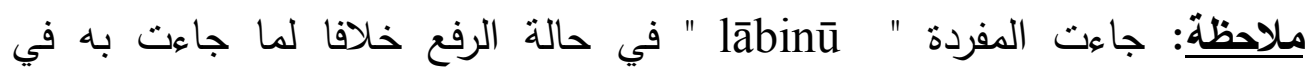
النصوص السابقة اذ جاءت بحالة الجر" "lābinī ". 


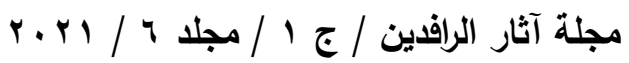

\section{NO.6 (IM.183844)}

Obv.

$$
\begin{aligned}
& 4 \text { ERÍN la-bi-nu } \\
& \text { mbe-la-nu-um } \\
& \text { a-na }{ }^{d} \text { MAR.TU-i-bi }
\end{aligned}
$$

Lo.ed.

$$
\text { il-li-ik }
$$

Rev.

5- ITU ŠU.NUMUN.A U 30 KAM

$$
\text { MU ALAM giš TUKUL SìG.GI }
$$

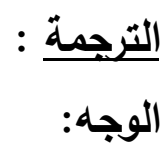

$$
\begin{aligned}
& \text { 1-بـ ؟ (عمال من) صانعي اللبن } \\
& \text { r- بيلانوم } \\
& \text { ץ- لِّمارتو -ايبي }
\end{aligned}
$$

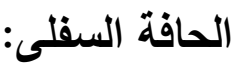

؟ - - عمل او أنجز

0- اليوم الثلاثون من شهر تموز

7- سنة التمثال حامل السلاح

$$
\begin{aligned}
& \text { " المعنى العام " }
\end{aligned}
$$

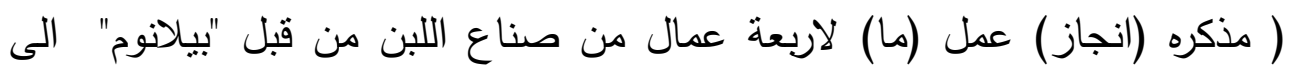

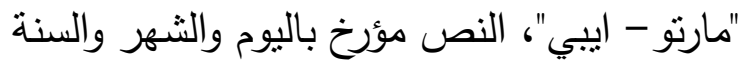

\section{NO.7 (IM.183841)}

Obv.

$$
\begin{aligned}
& 4 \text { ERÍN la-bi-ni } \\
& { }_{\mathrm{m}} \text { a-wi-il- }{ }^{\mathrm{d}} \text { na-bi-um } \\
& \text { a-na }{ }^{\mathrm{d}} \text { MAR.TU-i-bi }
\end{aligned}
$$

Lo.ed.

$$
\text { il-li-ik }
$$

Rev.

5- ITU ŠU.NUMUN.A U ${ }_{4} 21 \mathrm{KAM}$

MU ALAM giš TUKUL SÌG.GI 


$$
\begin{aligned}
& \text { 1- بـ ع (عمال من) صانعي اللبن } \\
& \text { r- آويل -نابيوم } \\
& \text { ب- الى مارنو - ايبي تئي }
\end{aligned}
$$

$$
\text { ع - عملَ او أنجزَ }
$$

$$
\text { ج- اليوم الواحد والعشرون من شهر تموز }
$$

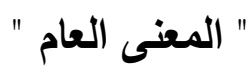

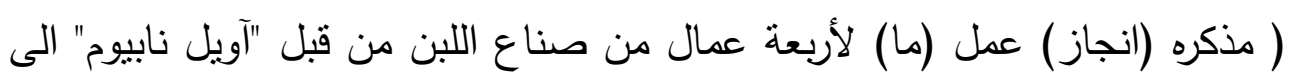

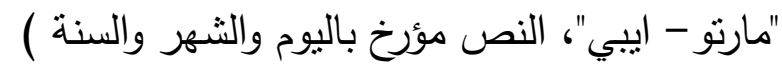

Obv.

\title{
NO.8 (IM.183843)
}

\author{
4 ERÍN la-bi-nu \\ mi-na-tum \\ a-na ${ }^{\mathrm{d}}$ MAR.TU-i-bi \\ il-li-ik
}

Rev.

5- ITU ŠU.NUMUN.A U 4 25KAM

MU Sa-am-su-i-lu-na LUGAL.E

ALAM giš TUKUL SİG.GI

$$
\text { اللوجه: }
$$

$$
\begin{aligned}
& \text { 1- بـ ء (عامل من) صانعي اللبن } \\
& \text { r- زيناتوم }
\end{aligned}
$$

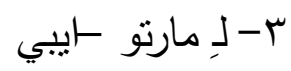

$$
\begin{aligned}
& \text { ع- عمل او انجزَ }
\end{aligned}
$$




$$
\text { 0- اليوم الخامس والعشرون من شهر تموز }
$$

آو V- سنة الملك سمسو - إيلونا ( الذي مثنّل في) تمثال حاملاً السلاح

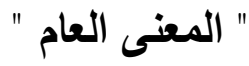

( مذكره (انجاز) عمل (ما) لاربعة عمال من صناع اللبن من قبل "زيناتوم" الى )

"مارتو - ايبي"، النص مؤرخ باليوم والثنهر والسنة )

ملاحظة : حول " lābin̄" بنظر النص رقم - م- في هذه البحث .

\section{"شرح المفردات"}

Y Sa-am-su-i-lu-na - اسم علم مذكر مركّب ، بمعنى: " شمس الهنا " ، مؤلف من

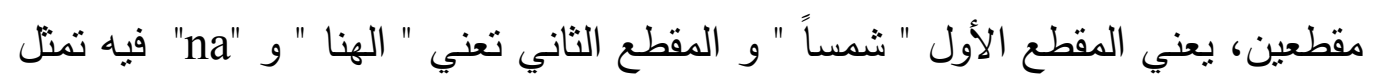

ضمير التملك للشخص الأول الجمع المذكر (34).

يوجد ضمير المتكلمين "na" بكثرة في الأسماء الآمورية(35).

: مفردة سومرية تعني: " ملكاً " و يقابلها في الأكدية " SUarrum " ، اما "EAL.E أداة للفاعل في حالة المفرد ، ومعناها العام "الملك"(36).

Obv.

\section{NO.9 (IM.183859)}

$$
\begin{aligned}
& 2 \text { ERÍN la-bi-ni } \\
& \text { mbe-la-nu-um } \\
& \text { a-na }{ }^{\mathrm{d}} \text { MAR.TU-i-bi }
\end{aligned}
$$

Lo.ed.

$$
\text { il-li-ik }
$$

Rev.

5- ITU ŠU.NUMUN.A U 424 KAM

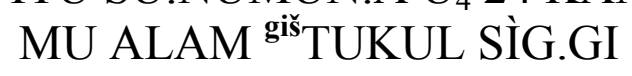

\section{: الترجمة

$$
\begin{aligned}
& \text { r- r (عاملان من) صانعي اللبن } \\
& \text { r - بيلانوم } \\
& \text { ب-لِِ مارتو - ليبي }
\end{aligned}
$$




\section{NO.10 (IM.183851)}

Obv.

$$
\begin{aligned}
& 2 \text { ERÍN la-bi-ni } \\
& { }_{\text {m }} \text { zi-na-tum } \\
& \text { a-na }{ }^{d} \text { MAR.TU-i-bi }
\end{aligned}
$$

il-li-ik

Rev.

5- ITU ŠU.NUMUN.A U 4 27KAM

MU ALAM ${ }^{\text {giš }}$ TUKUL SİG.GI

$$
\begin{aligned}
& \text { : الترحمة } \\
& \text { الوجه: }
\end{aligned}
$$

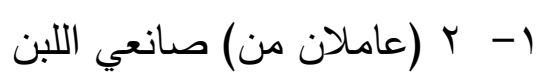

$$
\begin{aligned}
& \text { r- زيناتوم } \\
& \text { ب- لـِ مارتو لـيني } \\
& \text { ع- عمل او أنجزَ لمارئ }
\end{aligned}
$$




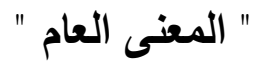 \\ ( مذكره (انجاز) عمل (ما) لعاملين من صناع اللبن من قبل "زيناتوم" الى "مارتو -

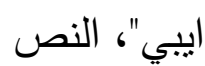 \\ مؤرخ باليوم والثـهر والسنة )}

الـهوامش:

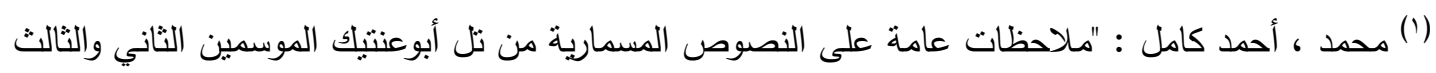

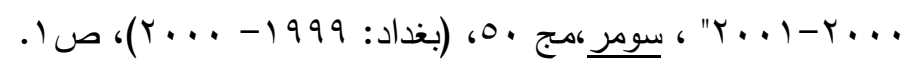

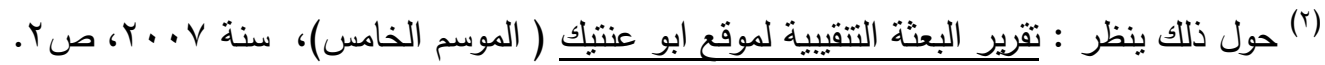

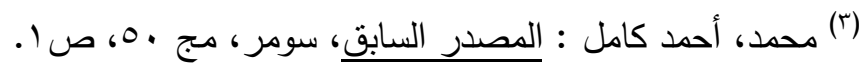

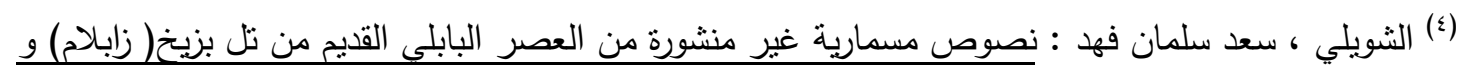

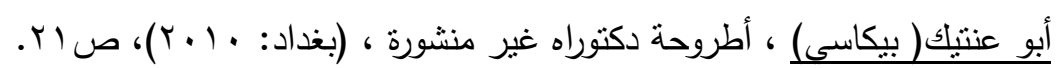

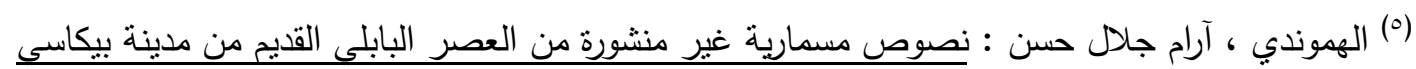
(تل ابو عنتيك) من المتحف العراقي، رسالة ماجسنير غير منشورة مقدمة الى جامعة صلاح الدين، (اربيل:

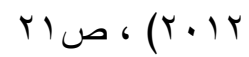
(7) محمد ، أحمد كامل: المصدر السابق ، صل ، ، كذللك ينظر : تقرير أعمال التتقيب لموقع ابوعنتيك للمواسم

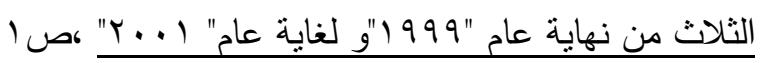

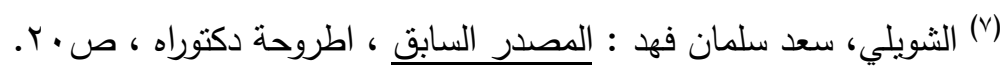

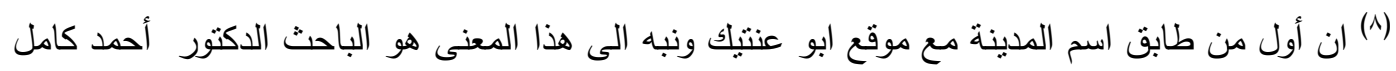

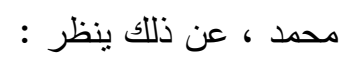

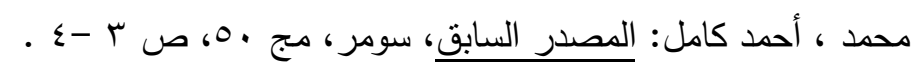
(9) Labat,R.: Manuel D’épigraphie Akkadienne, (Paris:1976), MDA , p.49², no: 15 (10) Gelb \& Others : The Chicago Assyrian Dictionary, (Chicago :1956f), CAD, K, p.253: b.

$$
\text { : حول صيغة كتابة اسم مدينة بيكاسي ينظر }
$$

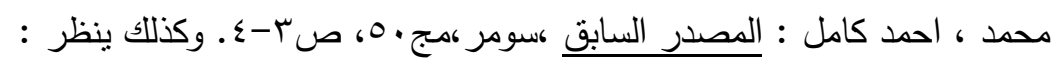

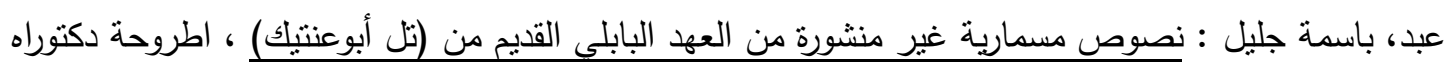

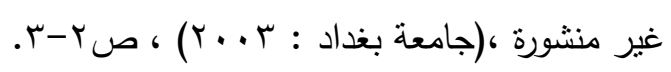

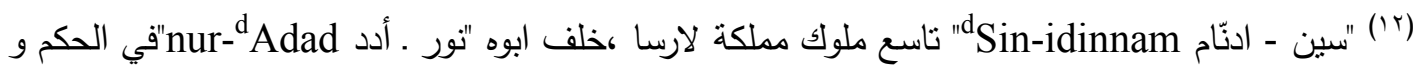

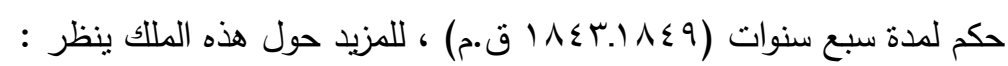
Fitzgerald, M.: The Rulers of Larsa p.98.

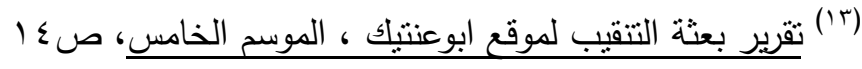

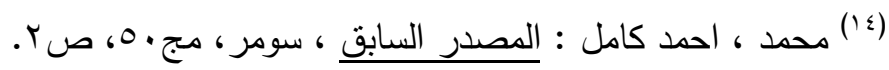

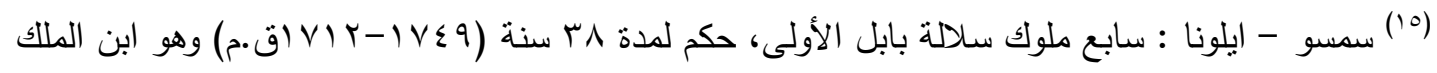

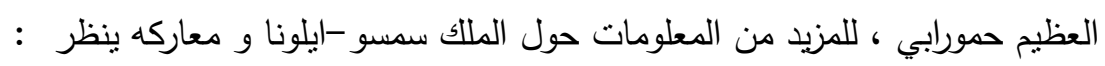


Civil, M. \& Othors: Ea a=nâqu, Aa a=nâqu, with their Forerunners and related texts, (Roma :1979), MSL 14 ,p.257, 2:228

Grégoire, J.-P.: Archives administratives sumériennes, (Paris 1970) $\underline{\mathbf{A A S}}$, no.177:4

$$
\begin{aligned}
& \text { (19) المتولي، نوالة أحمد محمود : مدخل في الحياة الاقتصادية لدولة أور الثالثه في ضوء الوثائق المسمارية، }
\end{aligned}
$$

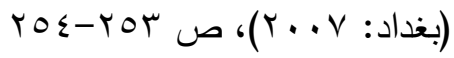

$$
\begin{aligned}
& \text { (20) }
\end{aligned}
$$

Weitemeyer, M ., Some Aspects of Hiring of workers in the Sippar region at the Time of Hammurabi ,(Copenhagen: 1962) , pp. 29, 58 .

Adams, R.: "An Interdiciplinary Overview of a Mesopotamian City and its inter lands", CDLI, 2008, p.20

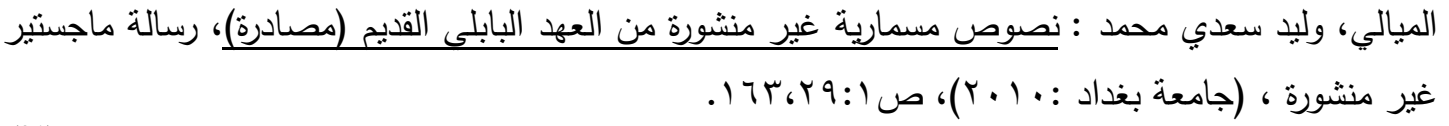

$$
\text { عن هذا الاسم ينظر : }
$$

Ranke, H.: Early Babylonian Personal Name, (Philadelphia:1906), EBPN , p. 70:a Dangin ,Th.: " Letters et Contracts De L' époque de la Premiere Dynastie Babylonienne ", Paris (1910), TCL 1, 147:24

Goetze, A.: "Thirty Tablets from the Reigons of Abī-ešuh and Ammī-ditānā", (New Haven :1948), JCS 2, p.105, 9:4

$$
\text { : (rr) }
$$

King, L. W.: Cuneiform Texts from Babylonian Tablets in the British Museum, (London: 1912), CT 33, 47a:8

Kraus, F.: Briefe aus dem British Museum, (Leiden:1977), $\underline{\text { AbB }} 7$, 76:1

Sigrist, M.: Old Babylonian Account Texts in the Horn Archaeology Museum, (Michigan: 1990), AUCT 4, p.42, 8:8

Birot, M.: LETTRES DE YAQQIM-ADDU, Gouverneur DE Sagarâtum, (Paris:1974), ARM 14, 4:12 \&17:9

Pfeiffer, R.H.: Excavations at Nuzi 2: The Archives of Shilwateshub, Son of the King. (Cambridge:1932), $\underline{\text { HSS }} 9$, 2:8

Langdon, S.: The Babylonian Menology and the Semitic Calenders " (London :1933), BMSC, p. 110

Al-Rawi ,F. \& Dalley ,S.: Old Babylonian Texts from Private Houses at Abu Habbah Ancient Sippar ", (London:2000) . E.DUBBA 7, p.156 


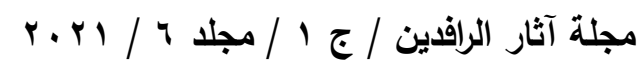

Cohen,M.: the Cultic Calindars of the Ancient Near East, (Bethesda, Maryland:

1993), Calindars, p.227

$$
\text { : (r) }
$$

NG 3, P.170

$$
\text { : (rv) }
$$

Leemens, W. F.: Legal and Economic Recoede from the kingdom of Larsa, (Leiden: 1954), SLB $1 / 2$, p. 47

CAD, k, p.50:a

Peat, J.: “A Collection of UR III Tablets", JCS 28, (USA:1976), p.221, 44:2

Roth, M.: "Reading Mesopotamian Law Cases PBS 5 100: A Question of Filiation", (Leiden: 2001), JESHO 44, p.285

$$
\text { : بنظر }
$$

$$
\text { (Leiden: 2001), JESHO } 44, \text { p.285 }
$$

$\underline{\text { CAD }}$, M1, p.72 ; MDA, p.135, no.295 ;

$$
\text { : (ra) }
$$

Genouillac, H.: Textes de l'epoque d'Agadé et de l'epoque d'Ur, (paris:1910-11), ITT 2, 3820:2

Legrain, L.: Business Document of the Third Dynasty of Ur, (London: 1947), UET 3, $985 ; 2$

Halloran, J.:Sumerian Lexicon, ( USA: 2006), SL, p.231

$$
\text { : حول هذه الصيغة التاريخية ينظر }
$$

Mercer,S.A.B: Sumero-Babylonian Year-Formula, (London:1946), SBYF, p.40, no. 575

Sigrist, M.: Mesopotamian year name, p.80

AUCT 4, p.66, 32: 8,9

$$
\text { : ينظر }
$$

Owen, D. I. \& Mayer, R. H.: the Garšana Archives, ( Bethesda: 2007), CUSAS 3, 346:col.2:12

Gelb, I. J.: Sargonic Texts in the Ashmolean Museum,Oxford (Chicago :1970), MAD $5,73: 5$

Schorr, M.: Urkunden des Altbabylonian Zivil - und prozessechts, (Leipzig: 1913), $\underline{\text { VAB } 5, p .466}$

Sulaiman, A.: Astudy of Land Tenure in Old Babylonian period with Special Reference to the Diyala Region Based on published and unpublished Texts, ph.D Thesis, university of London, (London:1966), SLTOB, p.406

Greengus,S.: Old Babylonian Tablets from Ischchali and Vicinity, (Istanbul: 1979), OBTI, p.81

Delitzsch, F.: Vorderasitische Schriftdenkmaler der Koniglichen Museen zu Berlin, (Leipzig: 1909), $\underline{\mathbf{V S}}$ 8, 93:14 
EBPN, p. 140

Sigrist, M. \& Ozaki, T.: Neo -Sumerian Administrative Tablets from the Yale Babylonian Collection, (Madrid: 2009), BPOA 7, 3024:r

Grégoire, J.-P.: Contribution à l'Histoire Sociale, Économicue Politique et Culturelle du Proche- Orient Ancien, (Paris :1996) AAICAB 1/1, pl. 015, 1930-40

Durand, J. M.: Documents Cunéformes de la IVe Section de 1'Ecole pratique de hautes, etudes, tomi I: Catalogue et Copies Cunéformes, (Paris:1982), DoCu 1, 495 :

r. col.2:7

$$
\text { : "na " عن ضنظر المتكلمين (ro) }
$$

Huffman, H.B.:Amorite Personal Names in the mari Texts, (USA:1961), APN ,p.235.

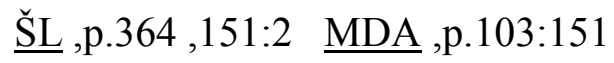




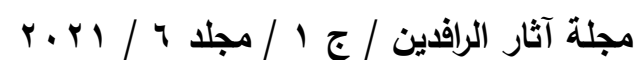

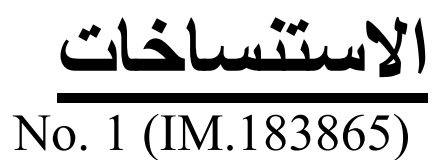

Obv.

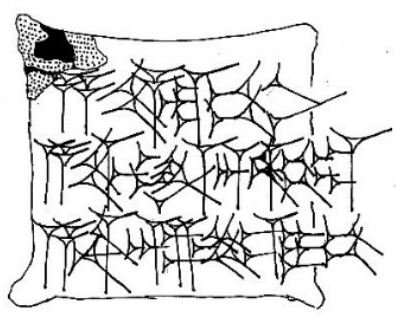

Lo.ed

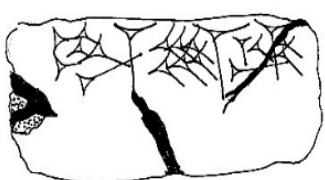

Rev.

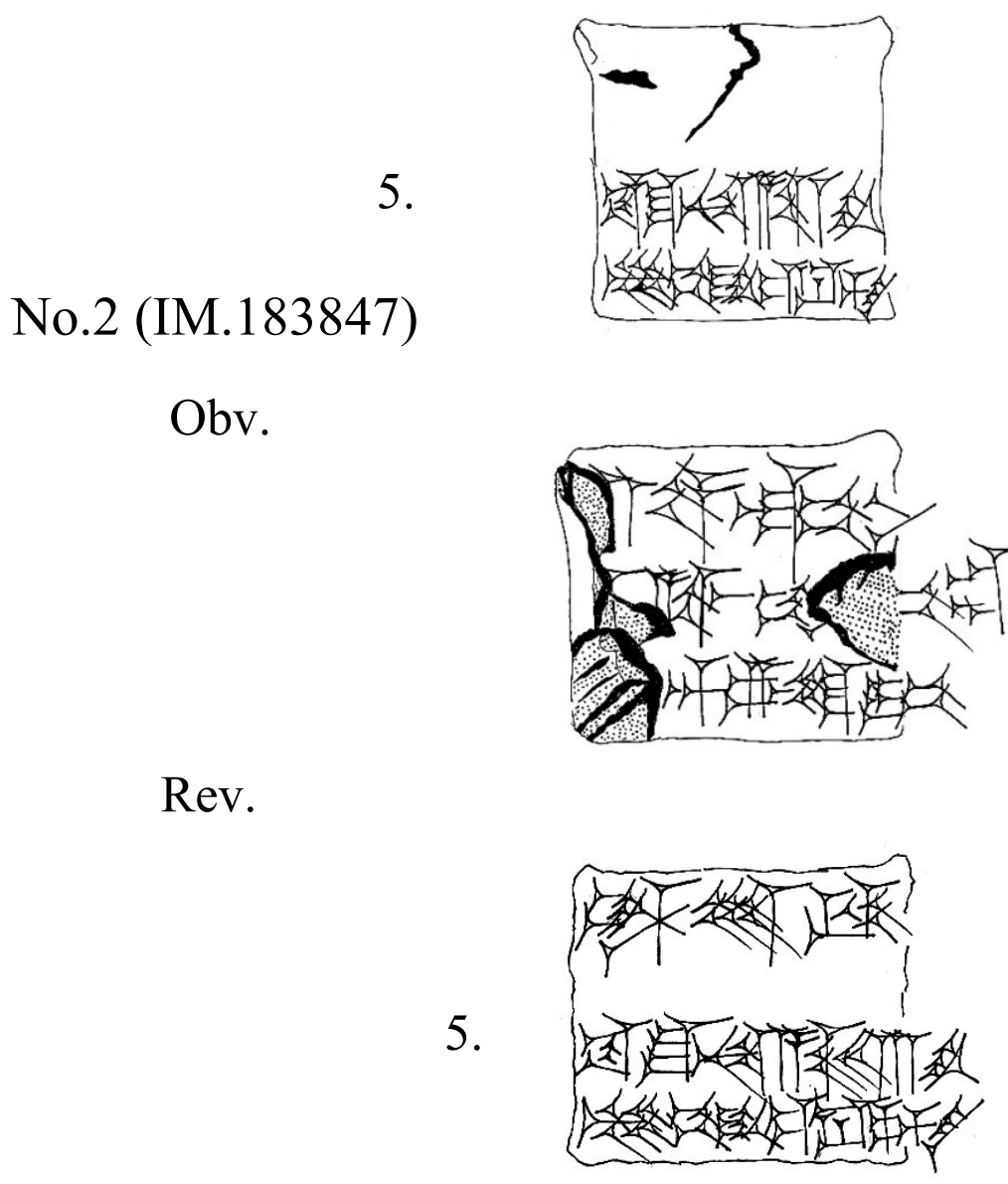

No.3 (IM.183840) 
د.آرام جلال حسن الهموندي

Obv.

5.

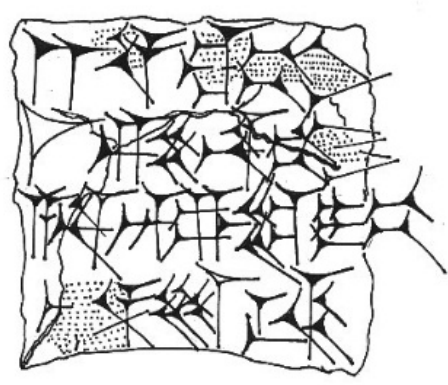

Rev.

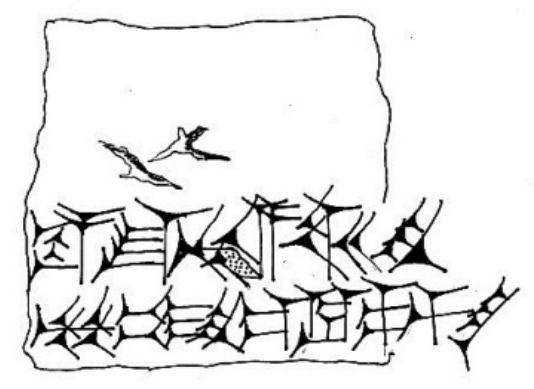

(IM.183849)

No.4

Obv.

Lo.ed.

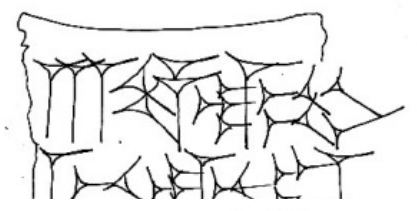

Rev.

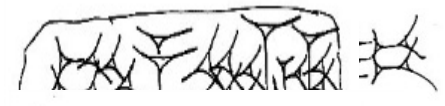

5.

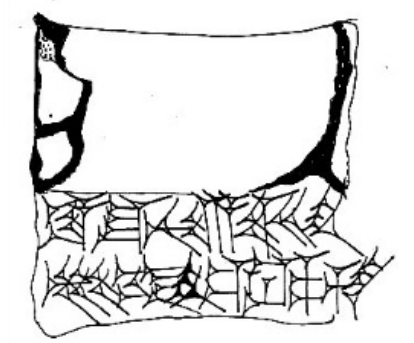

No.5 (IM.183853)

Obv.

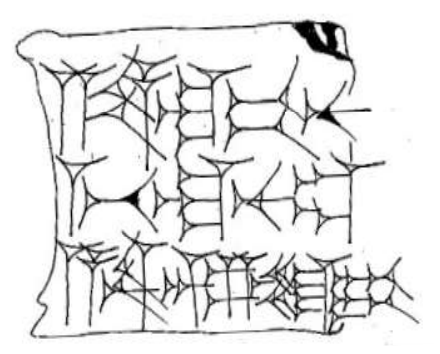




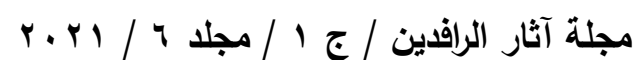

Rev.

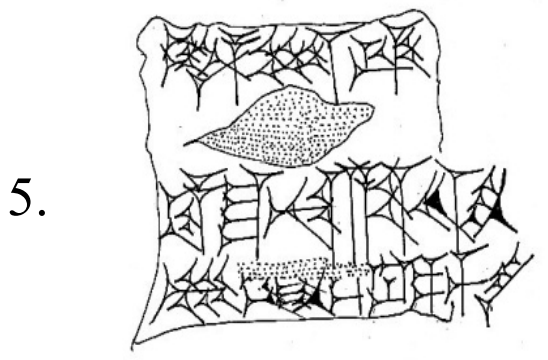

No.6 (IM.183844)

Obv.

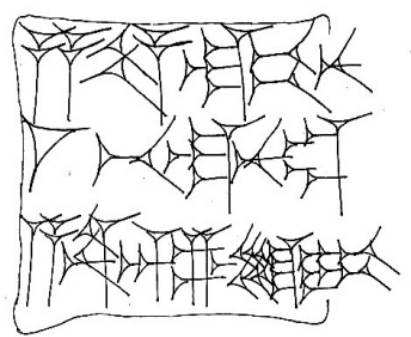

Lo.ed.

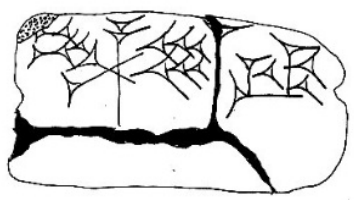

Rev.

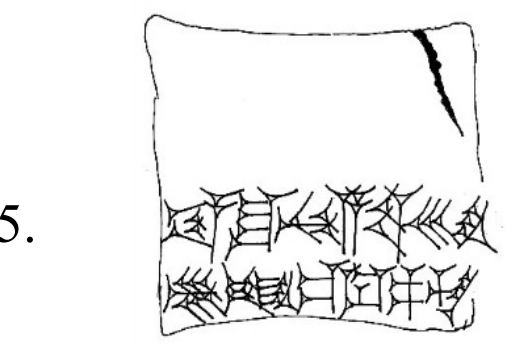

No.7 (IM.183841)

Obv.

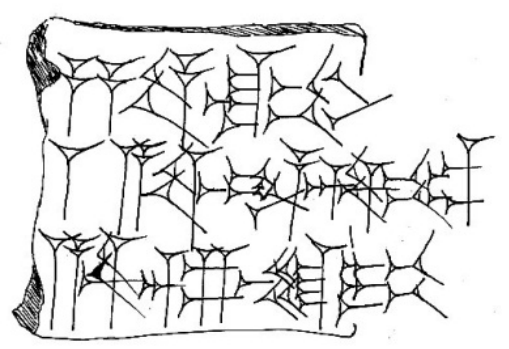


Lo.ed.

Rev.

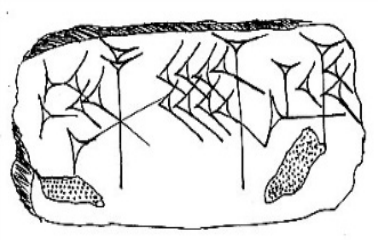

5.

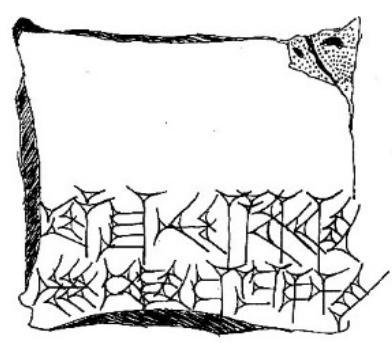

No.8 (IM.183843)

Obv.

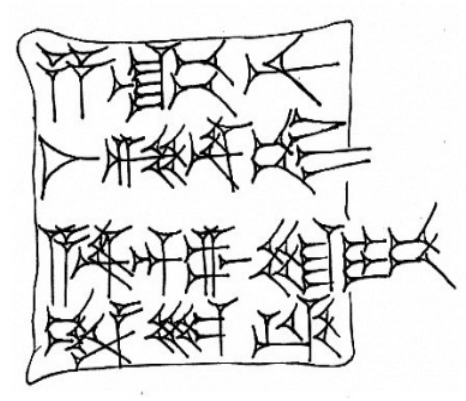

Rev.

No.9 (IM.183859)

Obv.

Lo.ed.
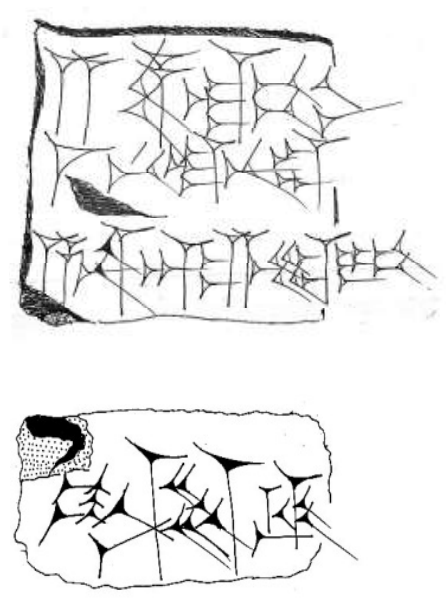


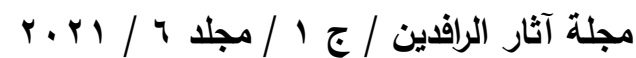

Rev.

5.

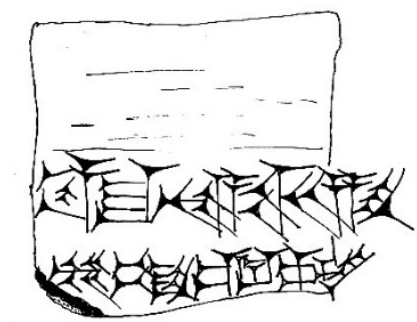

No.10 (IM.183851)

Obv.

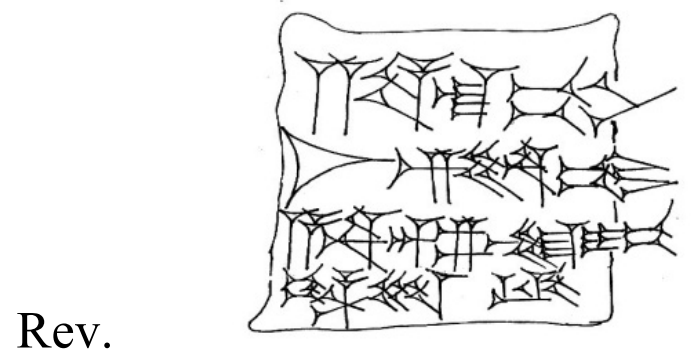

5.

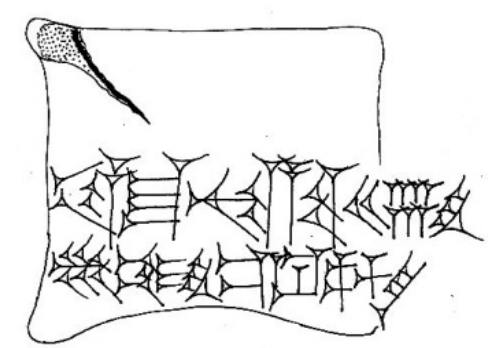


د.آرام جلال حسن الهموندي

وصولات انجاز اللبن من مدينة بيكاسي " تل ابوغنتيك"

" دراسة تحليلية لنصوص مسمارية غير منشورة "
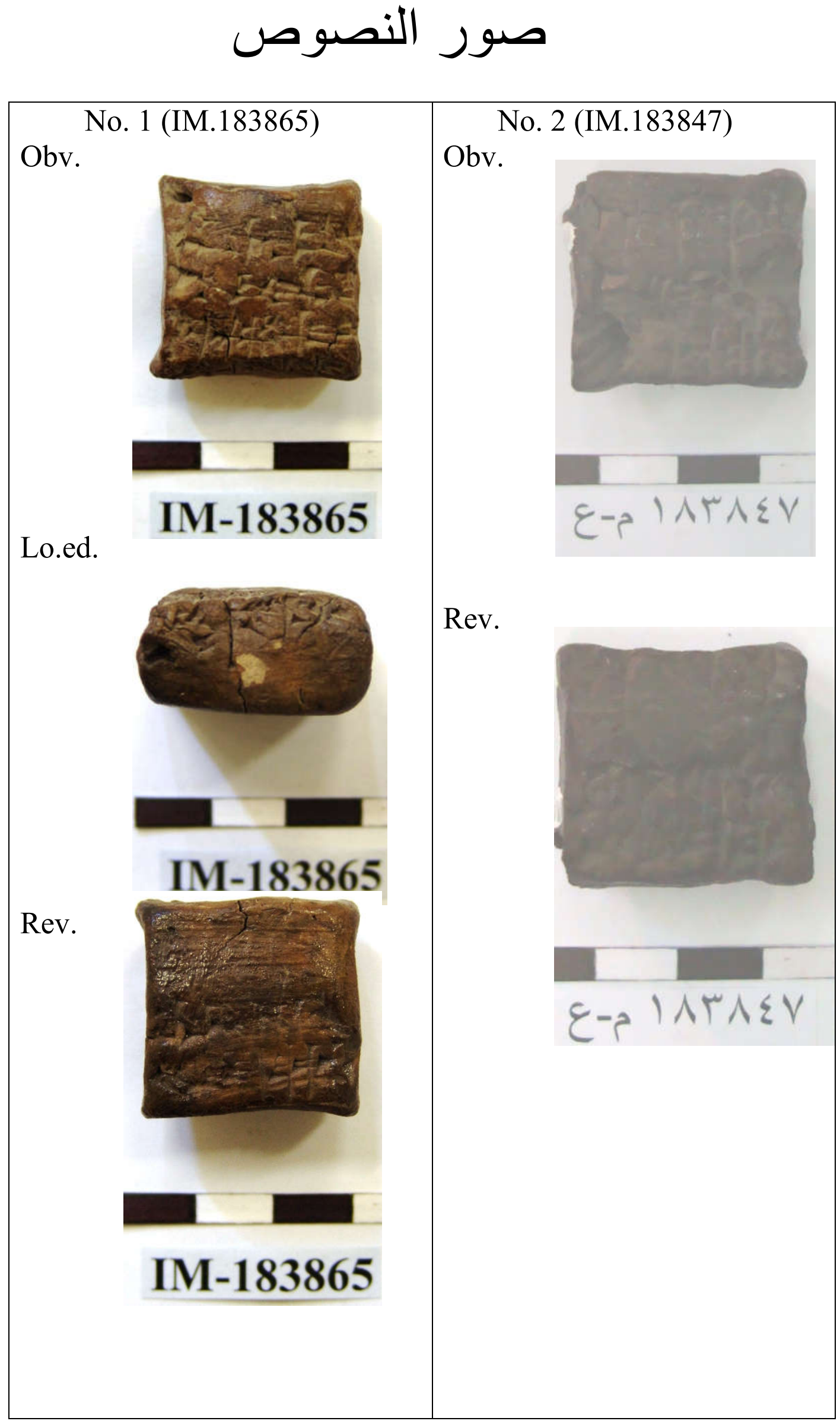


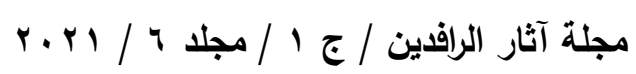

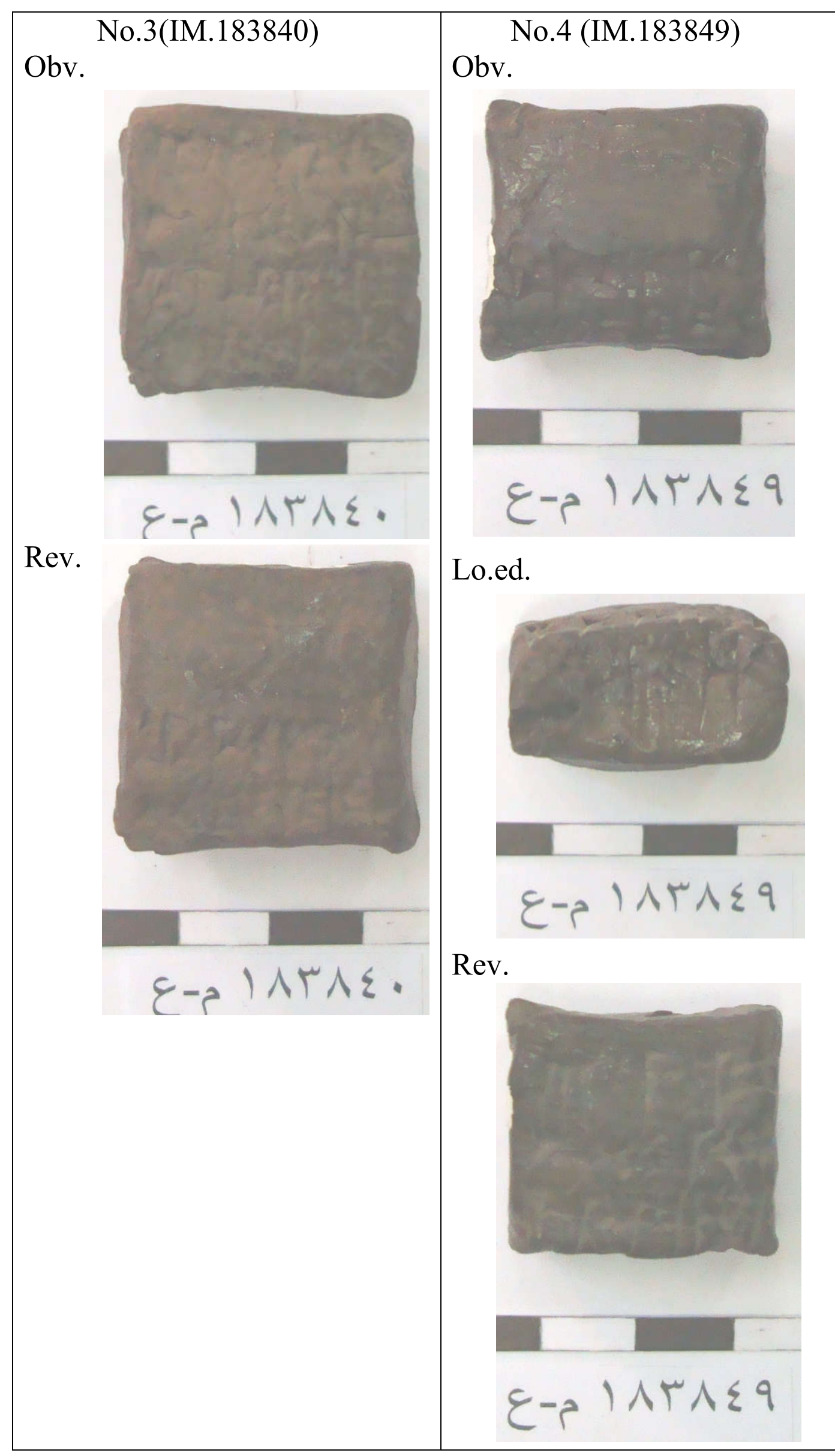

roN 
د.آرام جلال حسن الهموندي

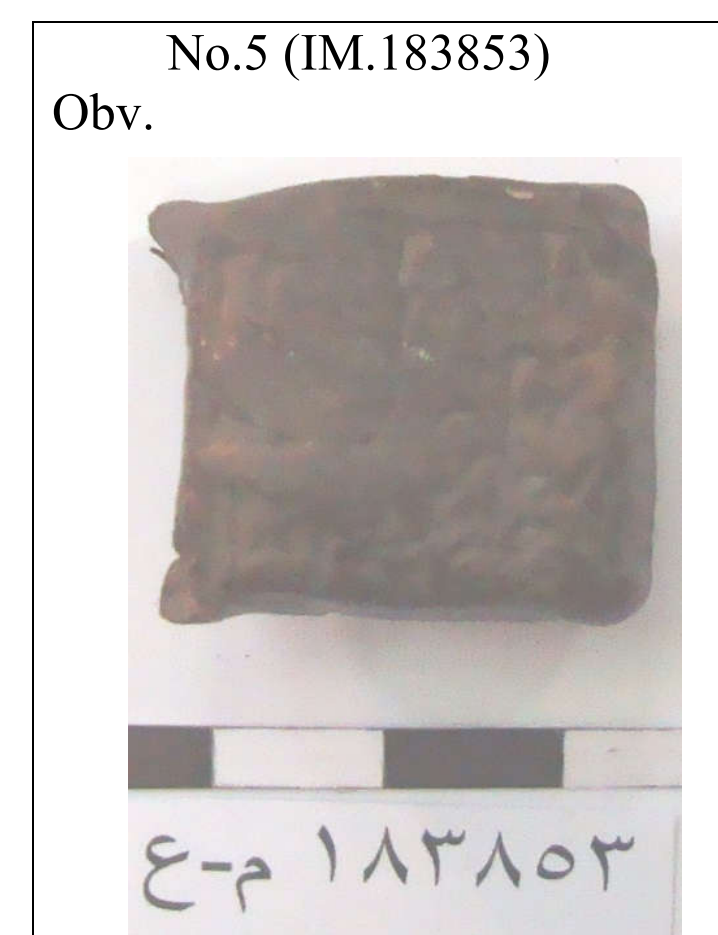

Rev.

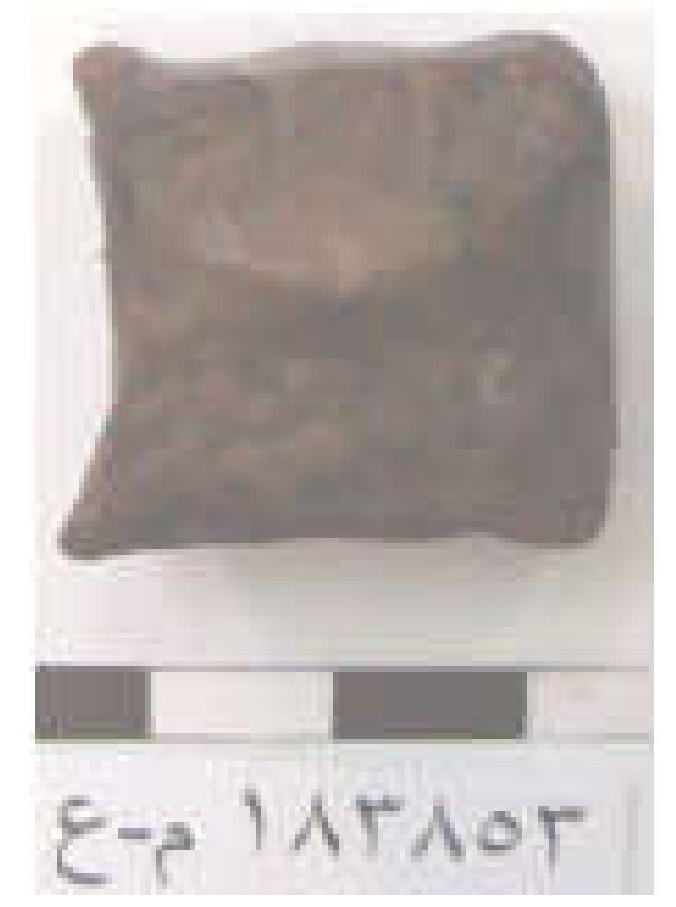

وصولات انجاز اللبن من مدينة بيكاسي " تل ابوغنيك"

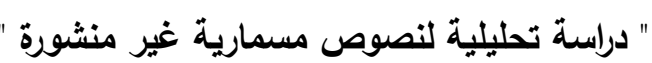

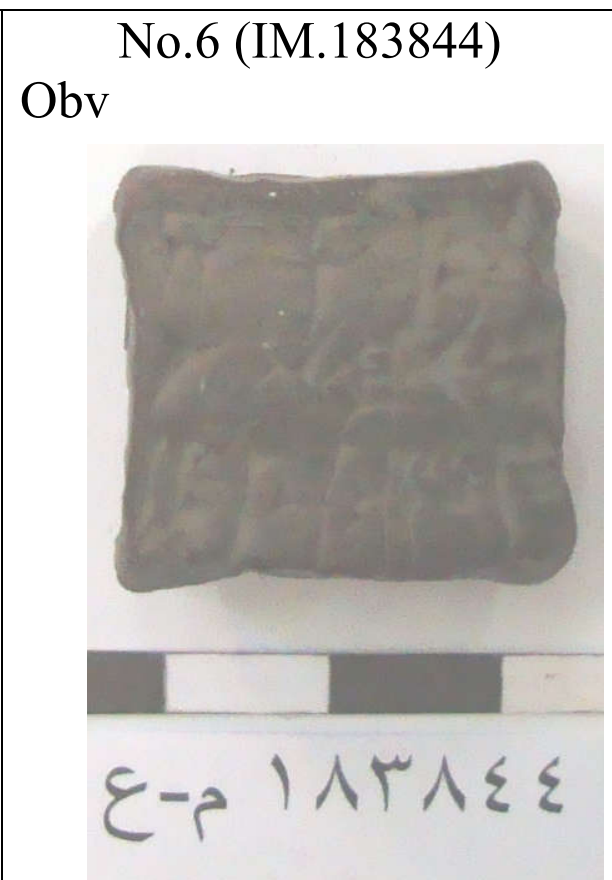

Lo.ed

$\varepsilon-5 \mid 1 r \lambda \varepsilon \varepsilon$

$\operatorname{Rev}$

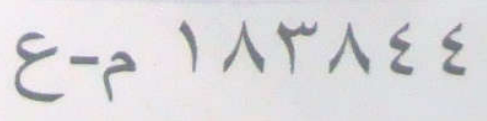

roq 


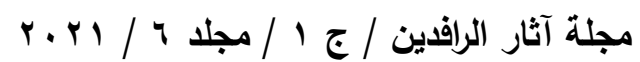

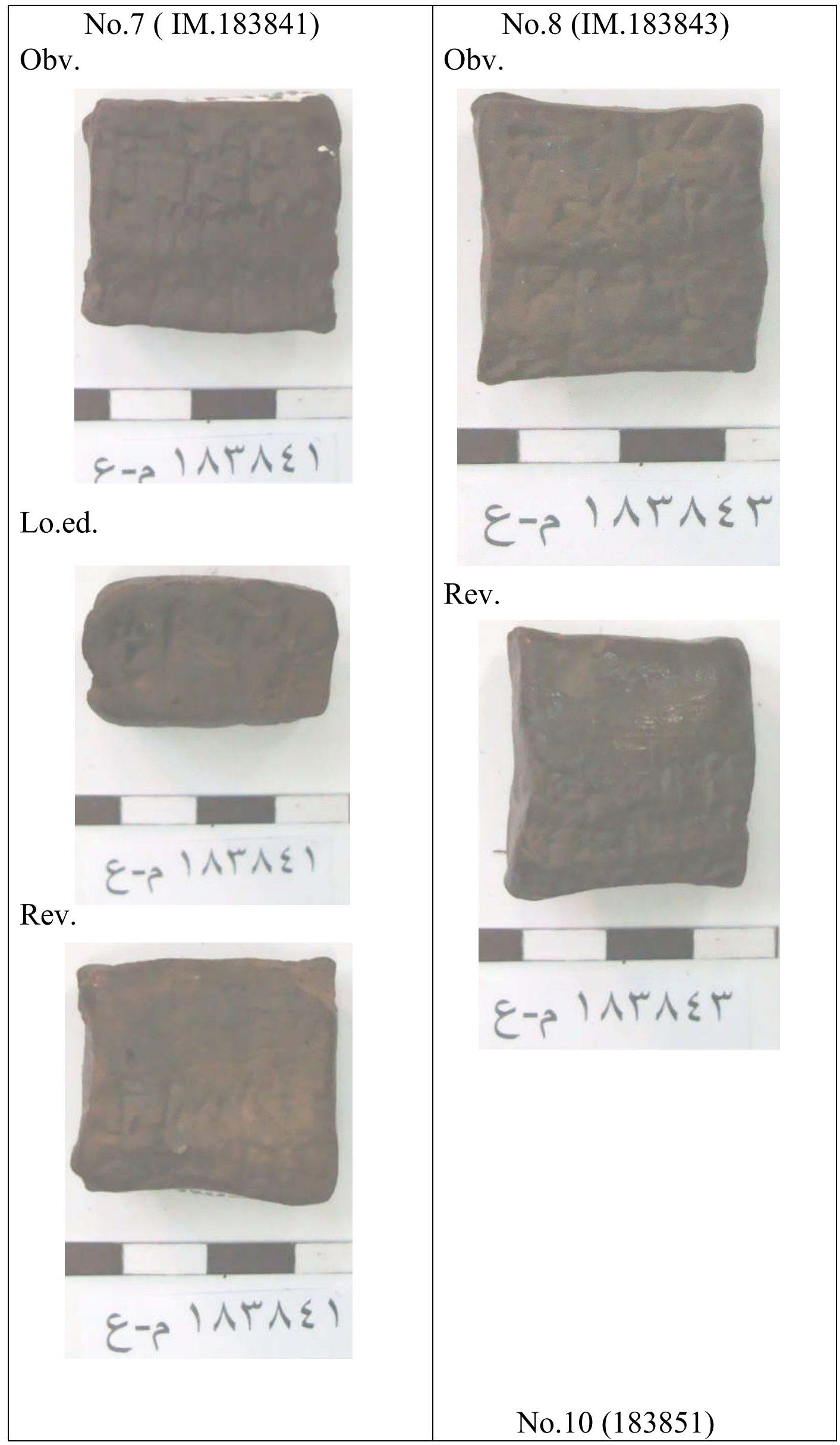


" دراسة تحليلية لنصوص مسمارية غير منشورة "

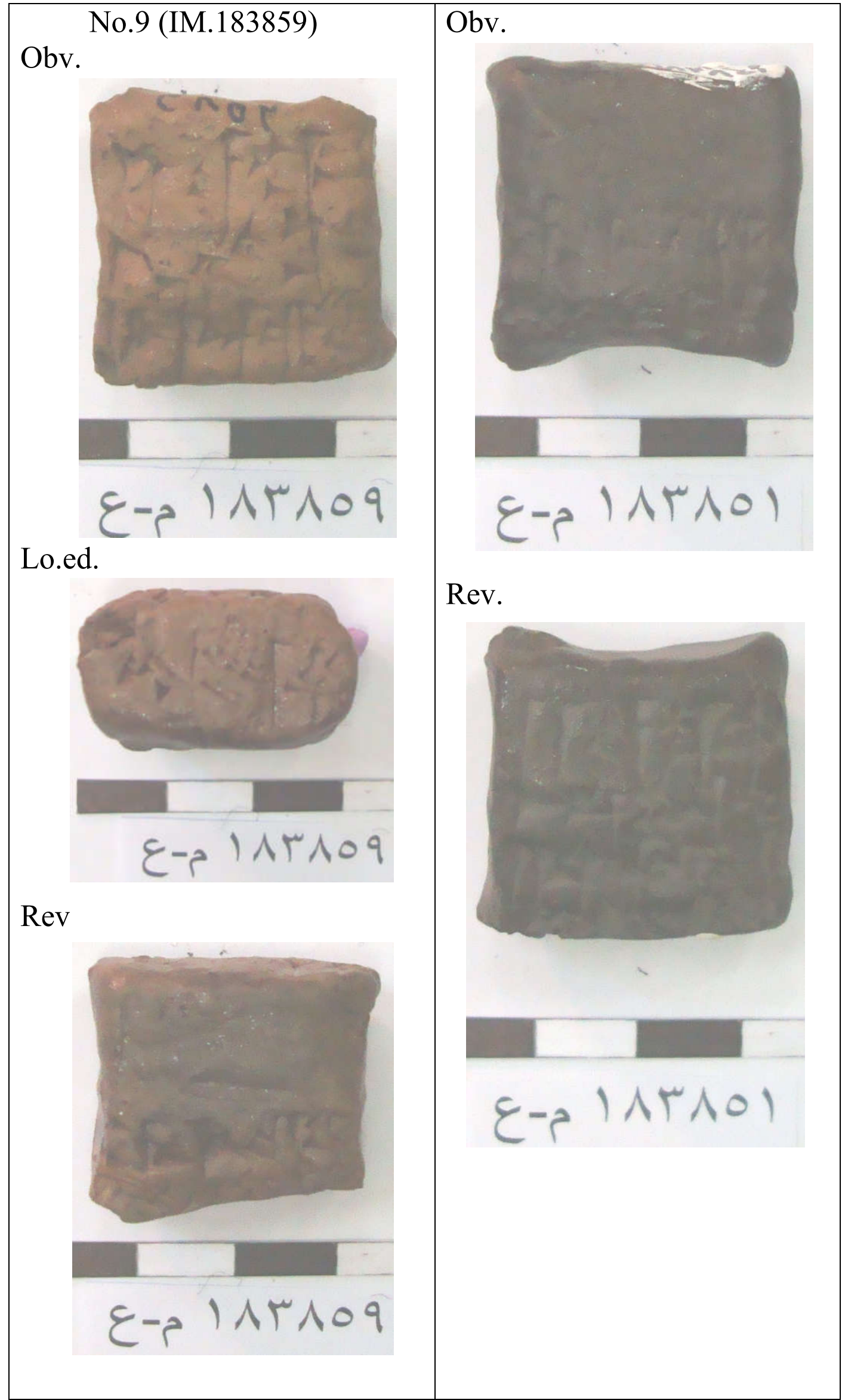




Contents

\begin{tabular}{|c|c|c|}
\hline Page & Research Name & $\overline{\text { Subject }}$ \\
\hline 1 & Prof. Khalid Salim Ismael & $\begin{array}{r}\text { Preface } \\
\end{array}$ \\
\hline $3-19$ & $\begin{array}{l}\text { Oday Abdulwahhab Al.Noamy } \\
\text { Prof. Khalid Salim Ismael }\end{array}$ & $\begin{array}{l}\text { From Epics of Kings in the Second and } \\
\text { First Millennium B.C. - An Analytical } \\
\text { Study }\end{array}$ \\
\hline $21-44$ & Prof. Dr. Farouk Ismail & The Ransom in Akkadian Texts \\
\hline $45-70$ & $\begin{array}{c}\text { Reem Mohammad Salih } \\
\text { Prof. Dr. Safwan Sami Saeed }\end{array}$ & $\begin{array}{l}\text { Assyrian's Concerns of Fear and Anxiety } \\
\text { Regarding Demons and Evil Spirits }\end{array}$ \\
\hline 71-91 & $\begin{array}{c}\text { Sondos Ali Hammadi } \\
\text { Prof. Dr. Yasser Al-Mashhadani }\end{array}$ & Sivas City before the Seljuk Rule \\
\hline $93-114$ & $\begin{array}{l}\text { Assist. Prof. Dr. Mohammed Kamil Rokan } \\
\text { Dr. Jumaa Heraz Al-Talbe }\end{array}$ & $\begin{array}{c}\text { Russian Excavations in Sinjar Region, } \\
\text { Northern Iraq }\end{array}$ \\
\hline $115-137$ & $\begin{array}{c}\text { Mustafa Ahmed Ali Al-Samarrai } \\
\text { Assist. Prof. Dr. Yasmine Abdul Karim } \\
\text { Mohammed Ali }\end{array}$ & $\begin{array}{c}\text { Residential Houses from the Moncorn } \\
\text { Assyrian Period (911-612) BC. M- } \\
\text { Elected Sites from the Makhul Dam } \\
\text { Project Area }\end{array}$ \\
\hline $139-164$ & $\begin{array}{l}\text { Falih Ghdwi Noman Al-Shammary } \\
\text { Assist. Prof. Dr. Haider Farhan Hussein } \\
\text { Al-Subaihawi }\end{array}$ & Heritage Mosques in Sinjar City \\
\hline $165-185$ & Assist Prof. Dr.Hussein .Y.Hazim & $\begin{array}{l}\text { Carbonated Grains and it's Role in } \\
\text { Archaeological Detection during } \\
\text { Prehistory - An Analytical Study }\end{array}$ \\
\hline $187-211$ & $\begin{array}{l}\text { Ashraf Aziz Abdul - Karim Al_Halay bik } \\
\text { Dr. Shakeeb Rashid Bashir Al- Fattah }\end{array}$ & $\begin{array}{l}\text { The Efforts of Scientific Families in } \\
\text { Building Schools and Teaching (Ibn Al- } \\
\text { Jawzi Family as a Model) }\end{array}$ \\
\hline 213-233 & $\begin{array}{c}\text { Asst. prof. Dr. Wasnaa Hasoun Younis } \\
\text { al-Aghaa }\end{array}$ & $\begin{array}{l}\text { Motives behind the Mummification of } \\
\text { Animals by the Ancient Egyptians }\end{array}$ \\
\hline $235-261$ & Dr. Aram J. Hassan Hamawand & $\begin{array}{l}\text { The Brick Completion Receipts from the } \\
\text { City of Pekasi, "Till Abu-Antik" } \\
\text { "An Analytical Study of Unpublished } \\
\text { Cuneiform Texts" } \\
\end{array}$ \\
\hline 263-279 & $\begin{array}{l}\text { Dr. Mohanad Khalaf Jamen Al shamari } \\
\text { Hanan Abdul-Hamzah Beuawe }\end{array}$ & $\begin{array}{l}\text { Unpublished Economic Texts from Ur III } \\
\text { Dynasty }\end{array}$ \\
\hline 281-302 & $\begin{array}{c}\text { Muthanna Saadoun Dhafer Al-Hindawi } \\
\text { Dr. Mahmoud Ibrahim Hussien } \\
\text { Dr. Dalia Mohamed El-Sayed } \\
\end{array}$ & $\begin{array}{l}\text { Demons and Evil Spirits in Ancient Iraq } \\
\text { in Light of Cuneiform Texts }\end{array}$ \\
\hline
\end{tabular}


12- The original research papers submitted to the magazine are not returned to their owners, whether published or not.

13- Tables and figures are numbered in a row according to their appearance in the research, provided with titles, submitted with separate papers, blueprints are submitted in black ink and images to be in high resolution.

14- The marginal numbers are written in parentheses and are presented in series at the end of the research.

15- The full source name is indicated in the margin, with the abbreviated source in parentheses at the end of the margin.

16- The researcher is responsible for correcting the linguistic and typographical errors in his research.

17- The magazine operates according to self-funding. Therefore, the researcher bears the publication fees of $(100,000)$ one hundred thousand Iraqi dinars.

18- Each researcher shall be provided with one copy of his research. As for the full copy of the journal, it is requested from the magazine's secretariat and a price is determined by the Editorial Board.

19- The papers should be sent to the journal e-mail:

uom.atharalrafedain@gmail.com 


\section{Publishing rules in Athar Al-Rafedain Journal (AARJ):}

1- The journal accepts scientific research that falls in specializations:

- Ancient Archaeology and Islamic Archaeology .

- Ancient languages with their dialects and comparative studies.

- Cuneiform Inscriptions and ancient lines.

- Historical and cultural studies

- Archaeological geology.

- Archaeological survey techniques.

- Anthropological studies.

- Conservation and restoration.

2- Research papers shall be submitted to the magazine in both Arabic and English.

3- The research shall be printed on (A4) paper, word-2010 system, with double spaces between lines, Simplified Arabic font for Arabic language, Times New Roman for English language, delivered on $\mathrm{CD}$, and in two paper based copies.

4- The title of the research should be printed in the middle of the page, followed by the name of the researcher, his academic degree, his full work address, and e-mail.

5- The research should contain an abstract in Arabic and English languages, it shouldn't exceed (100) words.

6- The abstract of the research in English contains the title of the research, the name of the researcher, his academic degree, his full workplace, and his e-mail.

7- The research must include keywords related to the title of the research and its content.

8- That the research was not previously published or was submitted to obtain a degree or is derived from the intellectual property of another researcher, and the researcher must undertake this in writing when submitting it for publication.

9- The researcher is obliged to follow the correct scientific foundations in his research.

10- The researcher is obligated to amend his research terms to suit the experts 'suggestions and the method of publishing in the journal.

11- The number of research pages does not exceed (25) pages, and in case of exceeding the required number, the researcher shall pay an additional amount for each additional page. 


\author{
Arabic Language Expert \\ Dr. Maan Yahya Mohammed \\ Dep. Of Arabic Language /College of Arts / University of Mosul
}

\author{
English Language Expert \\ Assist. Lect. Ammar Ahmed Mahmood \\ Dep. Of Translation Language / College of Arts / University of Mosul
}

Design Cover

Dr. Amer Al-Jumaili 


\title{
$\underline{\text { Editorial Board }}$
}

\author{
Prof. Khalid Salim Ismael \\ Editor-in-Chief
}

\section{Assist Prof. Hassanein Haydar Abdlwahed \\ Managing Editor}

\section{Members}

Prof. Elizabeth Stone

Prof. Adeileid Otto

Prof. Walther Sallaberger

Prof. Nicolo Marchetti

Prof. Hudeeb Hayawi Abdulkareem

Prof. Jawad Matar Almosawi

Prof. Rafah Jasim Hammadi

Prof. Abel Hashim Ali

Assist Prof. Yasamin Abdulkareem Mohammed Ali

Assist Prof. Vyan Muafak Rasheed

Assist Prof. Hani Abdulghani Abdullah 



\section{Journal}

\section{Athar Al-Rafedain}

Accredited Scientific Journal

It Search's in Archaeology of Iraq and Ancient Near East

Published by College of Archaeology - University of Mosul

E-Mail: uom.atharalrafedain@gmail.com

Vol.6 / No.1

Rejab. 1442 A.H. / Feb. 2021 A.D. 

University of Mosuil College of Archaedogy

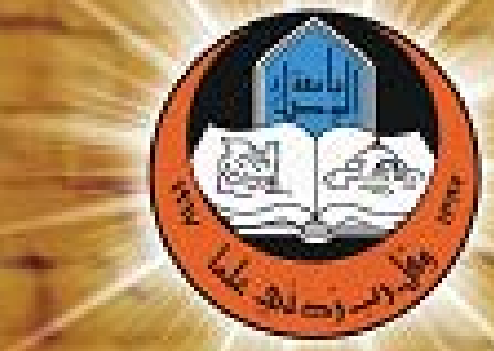

Ministry of Higher

Education and Sclentific

Research

ISSN $2304-103 X$

【RPG|

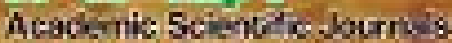

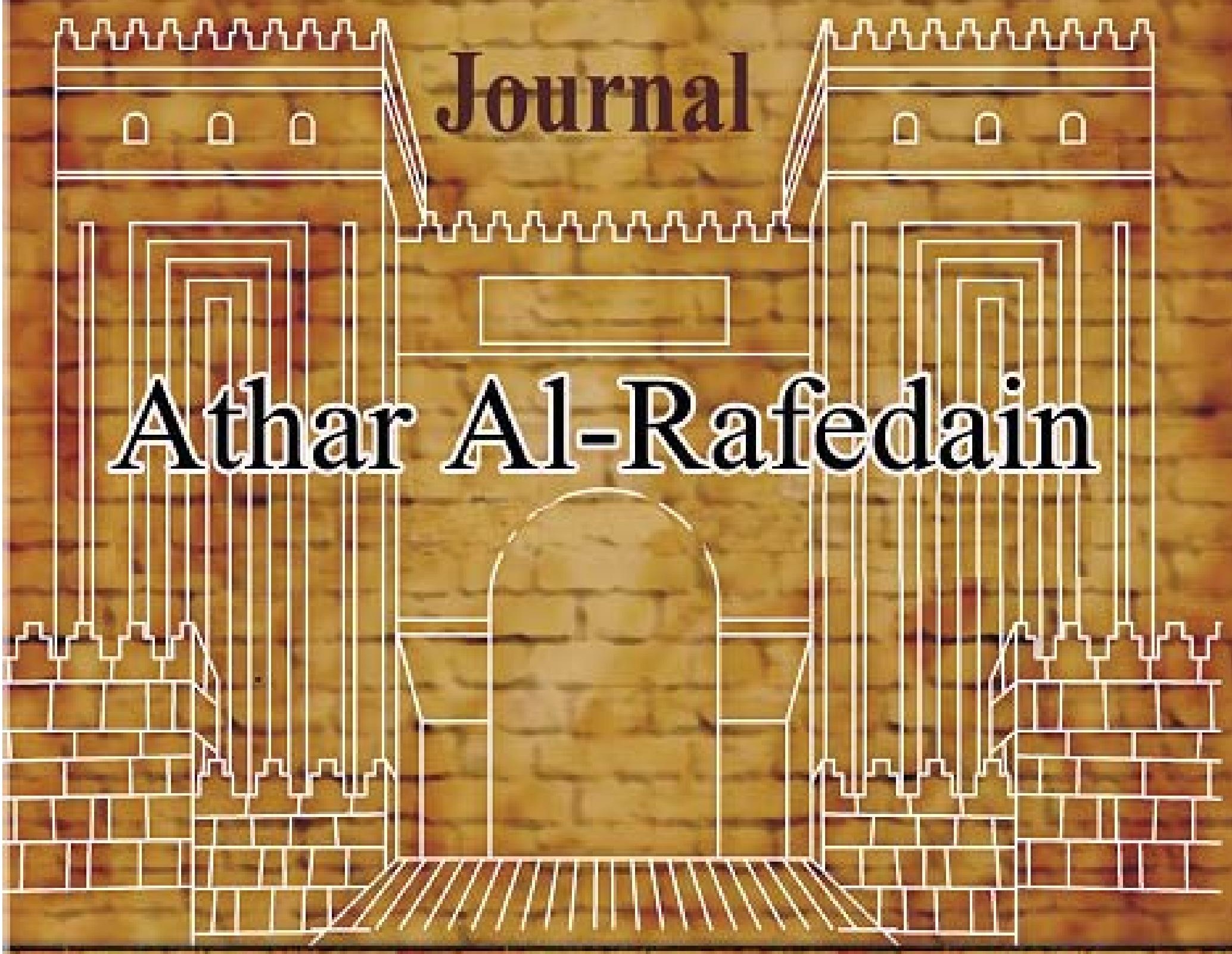

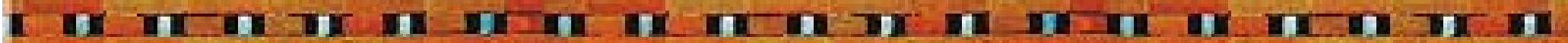

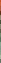

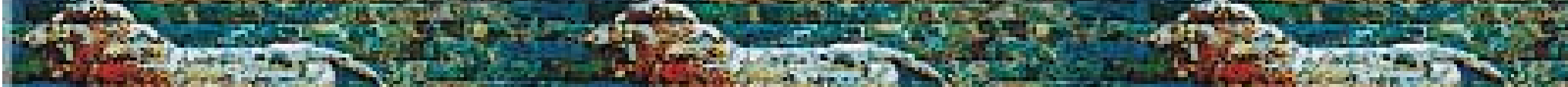

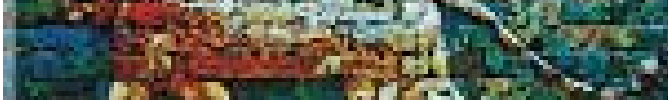
W.

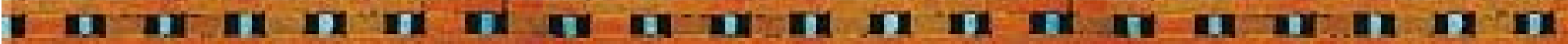

Accredited Scientific Journal it Search's in Archaeology of Iraq and Ancient Near East

Published College of Archaeology - University of Mosul / Vol.6/ No.1 / 1442 A.H. / 2021 A.D. 